\title{
Nuclear Hybrid Energy System FY16 Modeling Efforts at ORNL
}

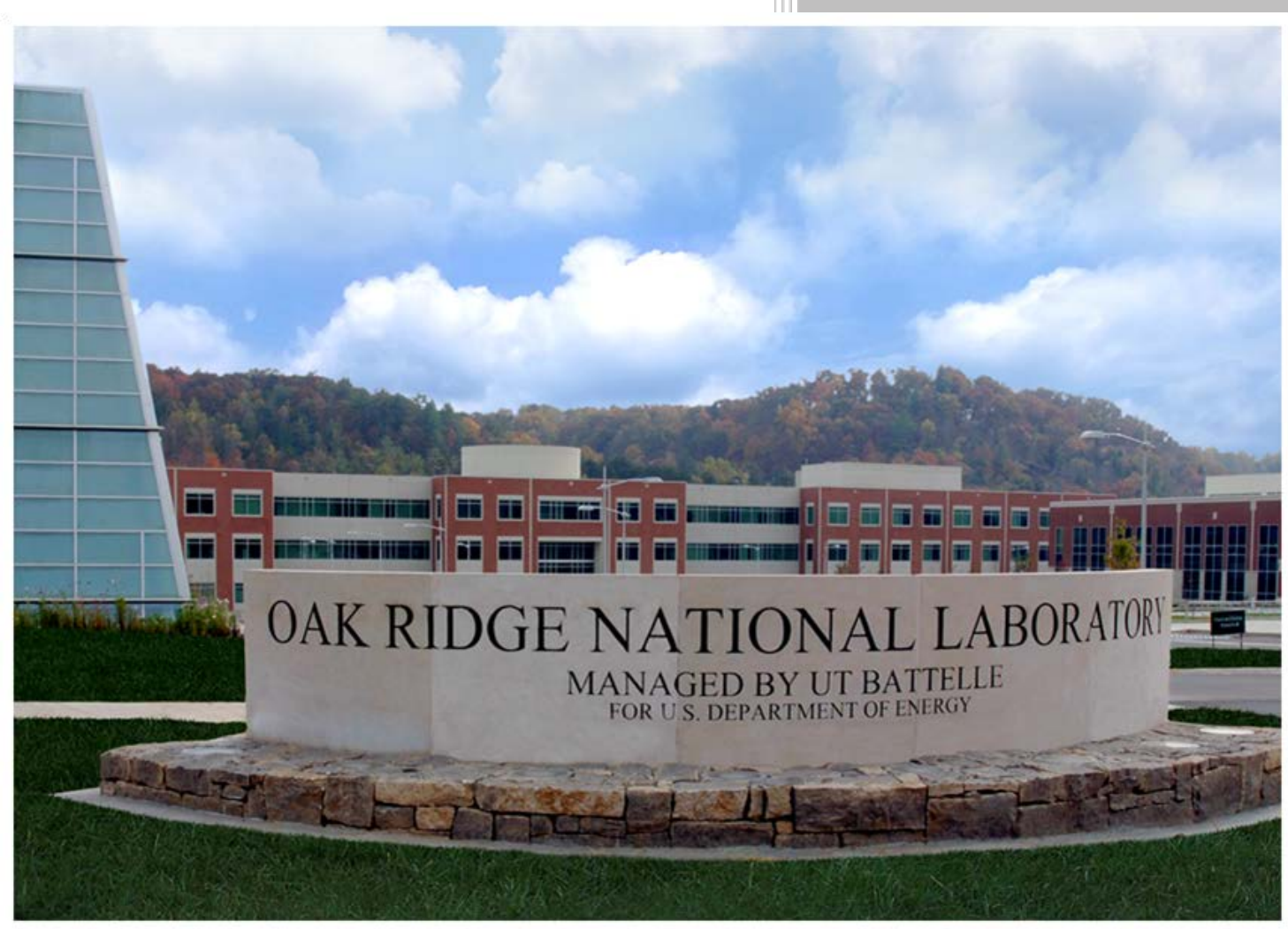

M. Sacit Cetiner M. Scott Greenwood T. Jay Harrison A. Lou Qualls Askin Guler Yigitoglu David L. Fugate

August 2016 


\title{
DOCUMENT AVAILABILITY
}

Reports produced after January 1, 1996, are generally available free via US Department of Energy (DOE) SciTech Connect.

\section{Website http://www.osti.gov/scitech/}

Reports produced before January 1, 1996, may be purchased by members of the public from the following source:

\author{
National Technical Information Service \\ 5285 Port Royal Road \\ Springfield, VA 22161 \\ Telephone 703-605-6000 (1-800-553-6847) \\ TDD 703-487-4639 \\ Fax 703-605-6900 \\ E-mail info@ntis.gov \\ Website http://www.ntis.gov/help/ordermethods.aspx
}

Reports are available to DOE employees, DOE contractors, Energy Technology Data Exchange representatives, and International Nuclear Information System representatives from the following source:

Office of Scientific and Technical Information

PO Box 62

Oak Ridge, TN 37831

Telephone 865-576-8401

Fax 865-576-5728

E-mail reports@osti.gov

Website http://www.osti.gov/contact.html

This report was prepared as an account of work sponsored by an agency of the United States Government. Neither the United States Government nor any agency thereof, nor any of their employees, makes any warranty, express or implied, or assumes any legal liability or responsibility for the accuracy, completeness, or usefulness of any information, apparatus, product, or process disclosed, or represents that its use would not infringe privately owned rights. Reference herein to any specific commercial product, process, or service by trade name, trademark, manufacturer, or otherwise, does not necessarily constitute or imply its endorsement, recommendation, or favoring by the United States Government or any agency thereof. The views and opinions of authors expressed herein do not necessarily state or reflect those of the United States Government or any agency thereof. 
Reactor and Nuclear Systems Division Electrical and Electronics Systems Research Division

NUCLEAR HYBRID ENERGY SYSTEMS FY16 MODELING EFFORTS AT ORNL

M. Sacit Cetiner

M. Scott Greenwood

T. Jay Harrison

A. Lou Qualls

Askin Guler Yigitoglu

David L. Fugate

Date Published: August 2016

Prepared by

OAK RIDGE NATIONAL LABORATORY

Oak Ridge, TN 37831-6283

managed by

UT-BATTELLE, LLC

for the

US DEPARTMENT OF ENERGY

under contract DE-AC05-00OR22725 



\section{CONTENTS}

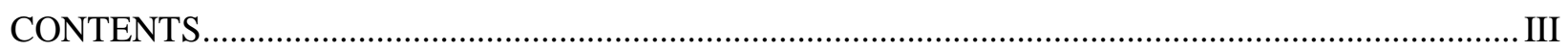

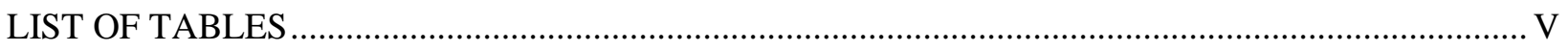

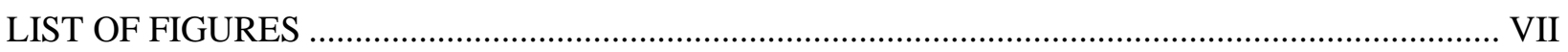

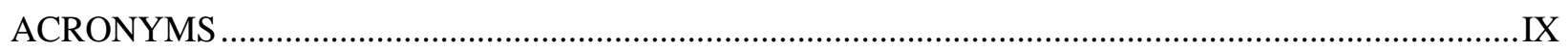

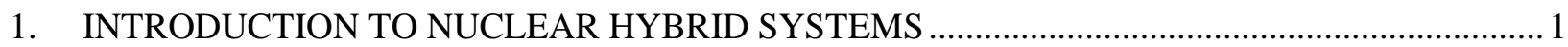

1.1 DEFINITION OF NUCLEAR HYBRID SYSTEMS ….......................................................... 1

1.2 CONTEXT OF NUCLEAR HYBRID SYSTEMS …....................................................... 1

1.3 PERFORMANCE GOALS OF NUCLEAR HYBRID SYSTEMS …....................................... 1

2. COMPONENTS OF A NUCLEAR HYBRID SYSTEM-THE BASE CASE................................ 3

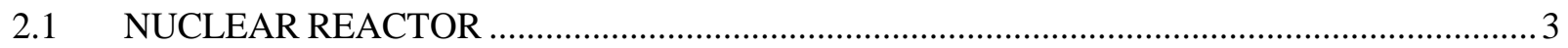

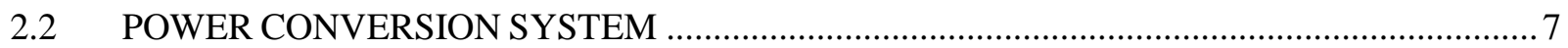

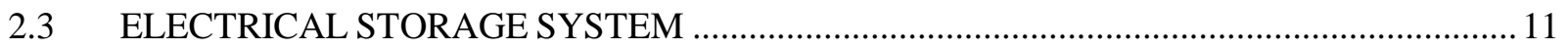

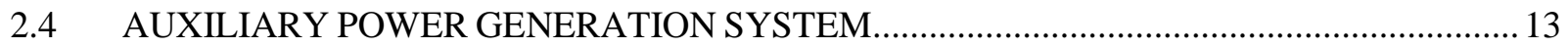

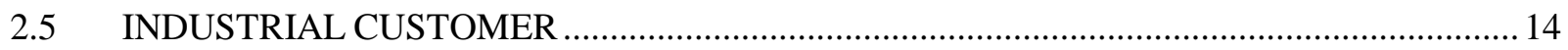

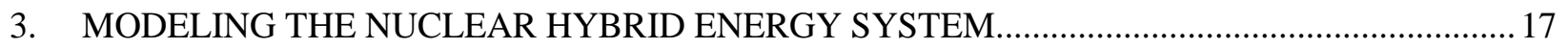

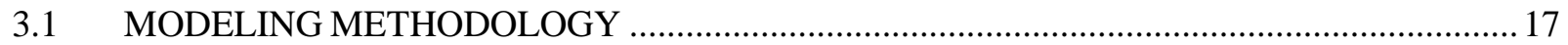

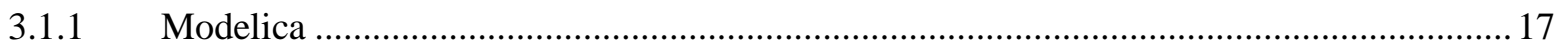

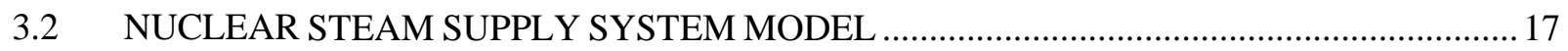

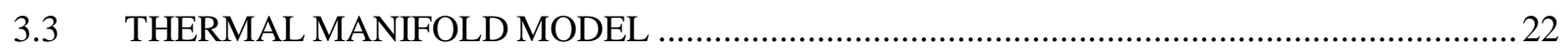

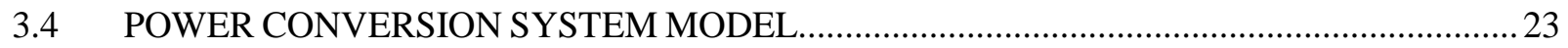

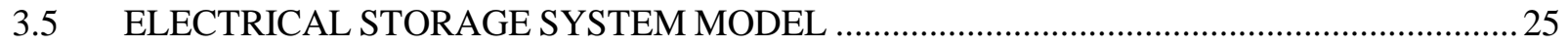

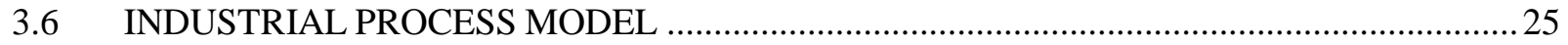

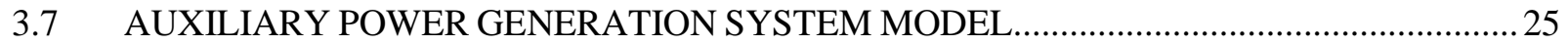

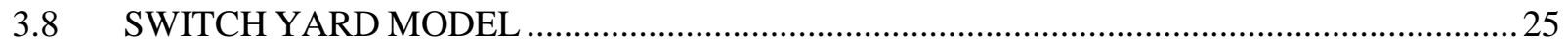

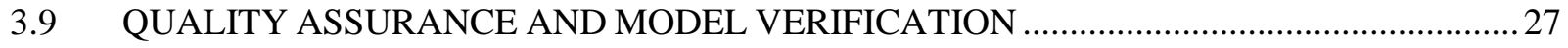

4. NUCLEAR HYBRID ENERGY SYSTEM INSTRUMENTATION AND CONTROL ....................29

$4.1 \quad$ NUCLEAR STEAM SUPPLY INSTRUMENTATION AND CONTROL ............................... 29

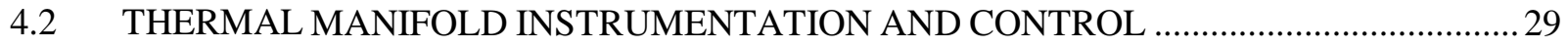

4.3 POWER CONVERSION SYSTEM INSTRUMENTATION AND CONTROL.......................29

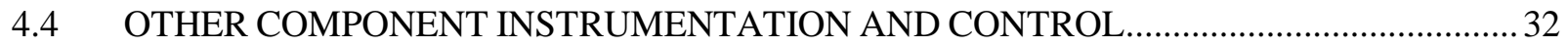

4.5 SUPERVISORY SYSTEM INSTRUMENTATION AND CONTROL ................................... 32

5. NUCLEAR HYBRID SYSTEM FIGURES OF MERIT ............................................................... 35

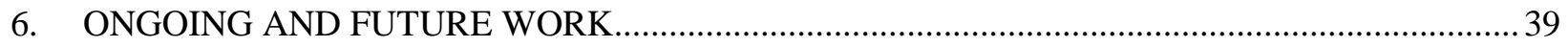

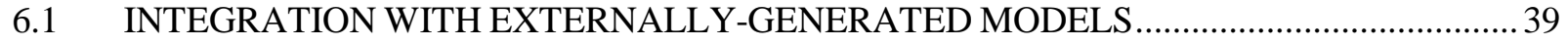

6.2 INTEGRATION WITH RAVEN

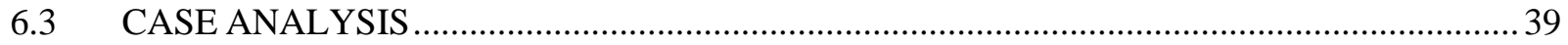

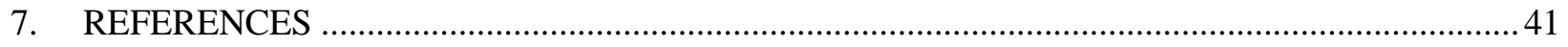

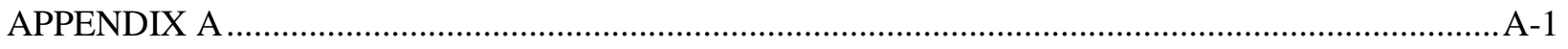





\section{LIST OF TABLES}

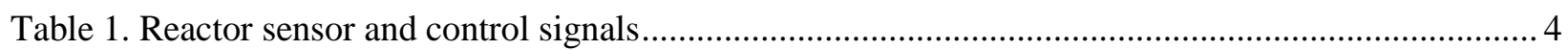

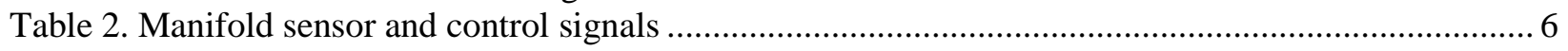

Table 3. Balance of plant sensor and control signals ........................................................................ 9

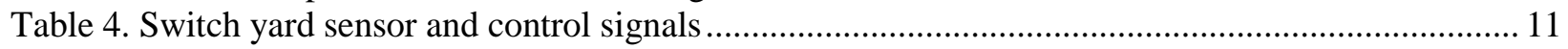

Table 5. Storage battery system sensor and control signals .................................................................. 12

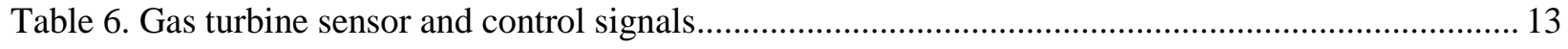

Table 7. Hydrogen production plant sensor and control signals ............................................................. 15

Table 8. International Reactor Innovative and Secure design parameters for the nuclear steam

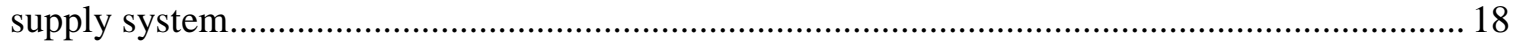

Table 9. Summary of design parameters for the International Reactor Innovative and Secure 1000 MWt nuclear reactor core

Table 10. Design parameters for the International Reactor Innovative and Secure helical coil steam generator 



\section{LIST OF FIGURES}

Fig. 1. Nuclear Hybrid Energy Systems Reactor Model......................................................................... 3

Fig. 2. Nuclear Hybrid Energy Systems Manifold Model. ...................................................................... 5

Fig. 3. Nuclear Hybrid Energy Systems balance of plant model. ............................................................ 8

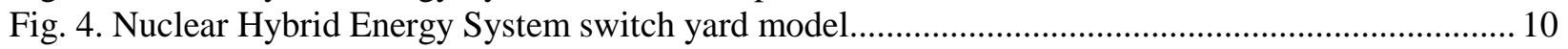

Fig. 5. Nuclear Hybrid Energy Systems battery system model. ....................................................... 12

Fig. 6. Nuclear Hybrid Energy System gas turbine model. ...................................................................... 13

Fig. 7. Nuclear Hybrid Energy System hydrogen production plant model.............................................. 14

Fig. 8. Modelica model of the International Reactor Innovative and Secure nuclear steam supply

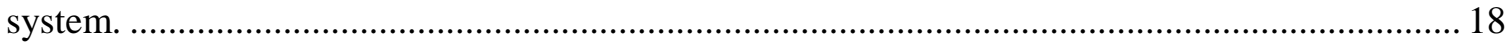

Fig. 9. Demonstration of linked lower level models.............................................................................. 19

Fig. 10. Design drawing of the International Reactor Innovative and Secure pressurizer [2]................... 20

Fig. 11. Modelica pressurizer model (left) and user definable parameters (right)................................... 21

Fig. 12. Steam generation temperature by normalized axial height....................................................... 22

Fig. 13. Steam quality by normalized height compared to [5].................................................................. 22

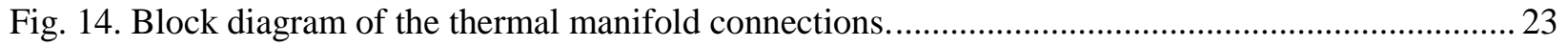

Fig. 15. Steam thermal manifold with valves and vessels to distribute flow............................................ 23

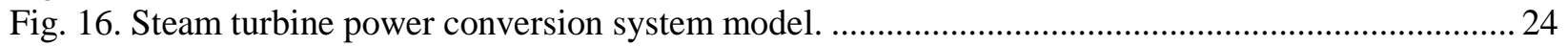

Fig. 17. Steam turbine with electrical generator system model............................................................... 25

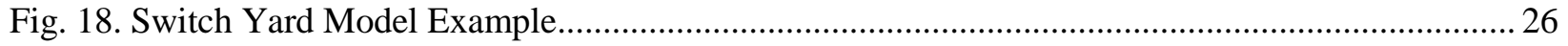

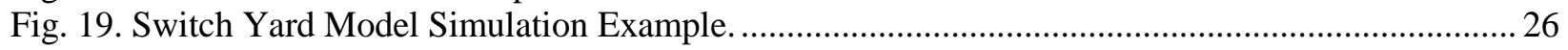

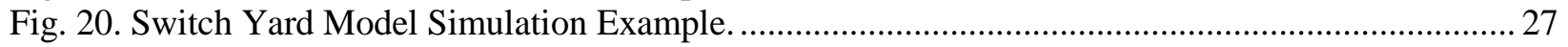

Fig. 21. Switch Yard Model Simulation Example............................................................................ 27

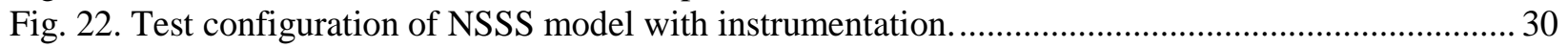

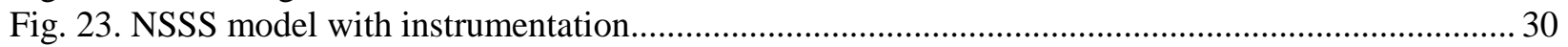

Fig. 24. NSSS model with instrumentation model test with reactivity change test case........................... 31

Fig. 25. NSSS model with instrumentation model test with steam generator input flow variation

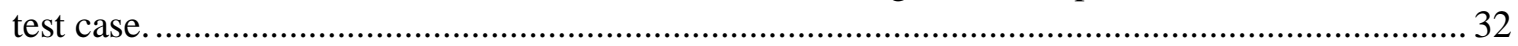

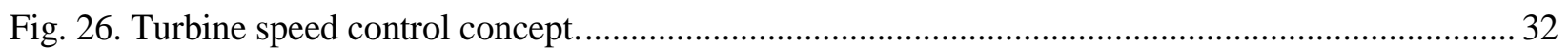

Fig. 27. Nuclear Hybrid Energy System model communication schematic. ......................................... 33

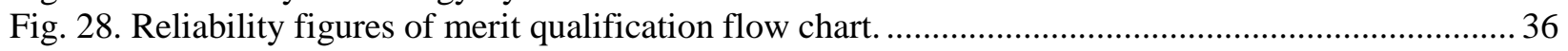





\section{ACRONYMS}

ANL

FOM

I\&C

INL

IPDV

IRIS

NHES

NSSS

ORNL

SG

ST

STDV
Argonne National Laboratory

figures of merit

instrumentation and control

Idaho National Laboratory

industrial process distribution valve

International Reactor Innovative and Secure

Nuclear Hybrid Energy System

nuclear steam supply system

Oak Ridge National Laboratory

steam generator

steam turbine

steam turbine distribution valve 


\section{INTRODUCTION TO NUCLEAR HYBRID SYSTEMS}

\subsection{DEFINITION OF NUCLEAR HYBRID SYSTEMS}

A nuclear hybrid system uses a nuclear reactor as the basic power generation unit. The power generated by the nuclear reactor is utilized by one or more power customers as either thermal power, electrical power, or both. In general, a nuclear hybrid system will couple the nuclear reactor to at least one thermal power user in addition to the power conversion system.

The definition and architecture of a particular nuclear hybrid system is flexible depending on local markets needs and opportunities. For example, locations in need of potable water may be best served by coupling a desalination plant to the nuclear system. Similarly, an area near oil refineries may have a need for emission free hydrogen production. A nuclear hybrid system expands the nuclear power plant from its more familiar central power station role by diversifying its immediately and directly connected customer base.

The definition, design, analysis, and optimization work currently performed with respect to the nuclear hybrid systems represents the work of three national laboratories. Idaho National Laboratory (INL) is the lead lab working with Argonne National Laboratory (ANL) and Oak Ridge National Laboratory. Each laboratory is providing modeling and simulation expertise for the integration of the hybrid system.

\subsection{CONTEXT OF NUCLEAR HYBRID SYSTEMS}

A nuclear hybrid system can provide options to avoid selling electricity in unfavorable electricity market conditions. This is especially important for deregulated wholesale electricity markets which have long price distribution tails. For example, the price rarely approaches \$0/MWeh [1], and the average for the wholesale price in some markets is around \$27/MWeh [1], but the high end can reach greater than $\$ 100 /$ MWeh [2]. On the low end of the distribution, the market prices may fall negative in some situations; this situation forces the nuclear reactor operators to decide whether to endure negative profit conditions or to curtail power generation. Neither approach is an attractive option. A potential benefit is to help accommodate an increased share of renewable power on the grid. As renewable generation increases, the volatility of the grid increases in response to the intermittent nature of the renewable generation. Typically, the grid volatility is smoothed by using natural gas generators as backups to the renewable sources because of their rapid response characteristics. However, the use of gas generators reintroduces carbon emissions that the renewable sources originally displaced. Nuclear reactor operators may not want to use their reactor in a load-following mode - even if they are technically capable of itbecause of concerns over thermal and chemical cycling but with the addition of a flexible resource in the form of a nuclear hybrid system, overall grid volatility can be tempered.

\subsection{PERFORMANCE GOALS OF NUCLEAR HYBRID SYSTEMS}

A goal of the Nuclear Hybrid Energy System (NHES) project is to show enhanced performance of integrated systems relative to independent stand-alone systems. The most direct measure, and thus comparison, of the performance is captured through cost analyses. The construction, operations, and fuel costs for the reactor, power conversion, and other coupled systems are typically well-documented, or at least can be estimated based on historical or other bases. Additionally, external costs such as carbon emissions can be accounted for based on estimated or assumed values. Comparison of other important figures of merit, such as system reliability or availability, or induced grid stability, requires additional estimation. 



\section{COMPONENTS OF A NUCLEAR HYBRID SYSTEM-THE BASE CASE}

The components described in Section 2 are described in greater modeling detail in Section 3.

\subsection{NUCLEAR REACTOR}

The reactor assumed for the initial NHES evaluation is a light water reactor, with the system model based on the IRIS design [3]. The use of this design leverages existing design studies and documentation for comparison of model results. Within this NHES configuration, the reactor secondary system steam is directed to a steam distribution manifold. From there, the thermal energy can be divided between a steam turbine for power conversion to electricity or to an industrial process; in this case a hydrogen production plant. The initial concept of the manifold is a set of steam valves directing fluid medium between the turbine and the hydrogen plant, and a common collection point for the returned cooled medium. The reactor and its connections to the manifold appear in Fig. $1 .{ }^{1}$ Table 2 shows the manifold and its connections to the reactor, the balance of plant, and the hydrogen plant. The parameters (variables), sensors (outputs), and controls (inputs) for the reactor are given in Table 1 with nominal values. Table 1 and the subsequent tables include some values marked as "TBD"; these values have not been determined or flown down into the model yet.

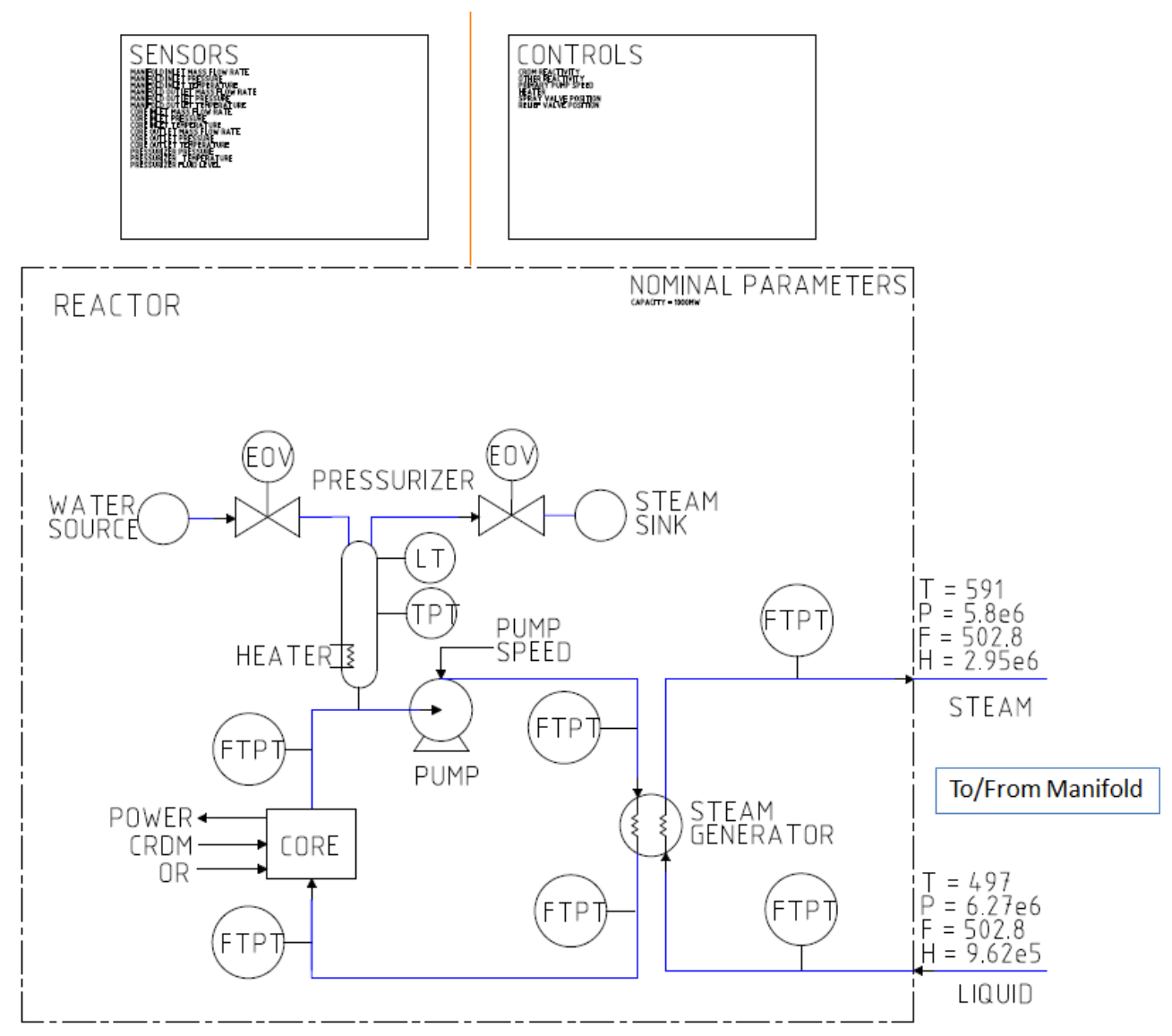

Fig. 1. Nuclear Hybrid Energy Systems Reactor Model.

\footnotetext{
${ }^{1}$ The figures in Section 2 are taken from a P\&ID for the NHES. This is attached in Appendix A.
} 
Table 1. Reactor sensor and control signals

\begin{tabular}{|c|c|c|}
\hline Variable/Measurement & Value & Unit(s) \\
\hline \multicolumn{3}{|l|}{ Parameters (variables) } \\
\hline Thermal Output & $1000 \mathrm{e} 6$ & $\mathrm{~W}$ \\
\hline \multicolumn{3}{|l|}{ Sensors (outputs) } \\
\hline \multicolumn{3}{|l|}{ External } \\
\hline Inlet (from Manifold): Mass Flow Rate & 502.8 & $\mathrm{~kg} / \mathrm{s}$ \\
\hline Inlet (from Manifold): Pressure & $6.27 \mathrm{E}+06$ & $\mathrm{~Pa}$ \\
\hline Inlet (from Manifold): Temperature & 497 & K \\
\hline Outlet (to Manifold): Mass Flow Rate & 502.8 & $\mathrm{~kg} / \mathrm{s}$ \\
\hline Outlet (to Manifold): Pressure & $5.80 \mathrm{E}+06$ & $\mathrm{~Pa}$ \\
\hline Outlet (to Manifold): Temperature & 591 & $\mathrm{~K}$ \\
\hline \multicolumn{3}{|l|}{ Reactor Core } \\
\hline Inlet: Mass Flow Rate & 4712 & $\mathrm{~kg} / \mathrm{s}$ \\
\hline Inlet: Pressure & $1.60 \mathrm{E}+07$ & $\mathrm{~Pa}$ \\
\hline Inlet: Temperature & 556 & $\mathrm{~K}$ \\
\hline Outlet: Mass Flow Rate & 4712 & $\mathrm{~kg} / \mathrm{s}$ \\
\hline Outlet: Pressure & $1.55 \mathrm{E}+07$ & $\mathrm{~Pa}$ \\
\hline Outlet: Temperature & 594 & $\mathrm{~K}$ \\
\hline \multicolumn{3}{|l|}{ Pressurizer } \\
\hline Pressure & $1.54 \mathrm{E}+07$ & $\mathrm{~Pa}$ \\
\hline Temperature & 617.5 & $\mathrm{~K}$ \\
\hline Fluid Level (from pressurizer inlet) & $1.68(0.34)$ & m (\%Liquid) \\
\hline \multicolumn{3}{|l|}{ Controls (inputs) } \\
\hline \multicolumn{3}{|l|}{ Reactor Core } \\
\hline Control Rod Drive Mechanism (CRDM, i.e., reactivity) & 0 & \\
\hline Other Reactivity & 0 & \\
\hline \multicolumn{3}{|l|}{ Pump } \\
\hline Primary Pump Speed & 1500 & RPM \\
\hline \multicolumn{3}{|l|}{ Pressurizer } \\
\hline Heater & 0 & $\mathrm{~W}$ \\
\hline Spray Valve Position & 0 & \% open \\
\hline Relief Valve Position & 0 & \% open \\
\hline
\end{tabular}




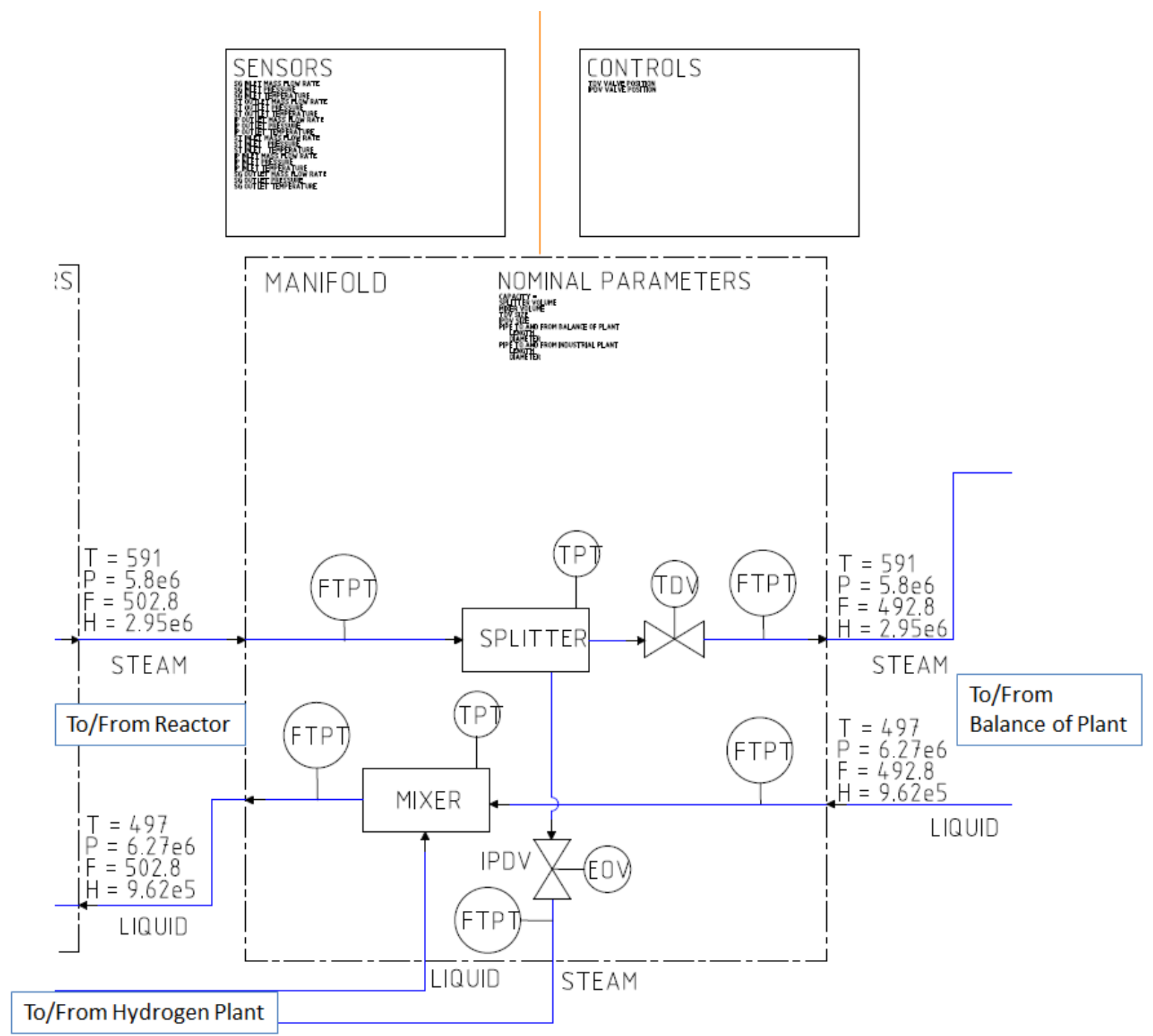

Fig. 2. Nuclear Hybrid Energy Systems Manifold Model.

The parameters (variables), sensors (outputs), and controls (inputs) for the manifold are given in Table 2 with nominal values. 
Table 2. Manifold sensor and control signals

\begin{tabular}{|c|c|c|}
\hline Variable/Measurement & Value & Unit(s) \\
\hline \multicolumn{3}{|l|}{ Parameters (variables) } \\
\hline \multicolumn{3}{|l|}{ General } \\
\hline Splitter Volume & 1 & $\mathrm{~m}^{3}$ \\
\hline Mixer Volume & 1 & $\mathrm{~m}^{3}$ \\
\hline $\begin{array}{l}\text { Steam Turbine Distribution Valve (STDV) Size } \\
\text { Based on industrial process and steam turbine sizing }\end{array}$ & Large & \\
\hline $\begin{array}{l}\text { Industrial Process Distribution Valve (IPDV) Size } \\
\text { Based on industrial process and steam turbine sizing }\end{array}$ & Small & \\
\hline \multicolumn{3}{|l|}{ Pipe to/from Balance of Plant } \\
\hline Velocity Limit & 4 & $\mathrm{~m} / \mathrm{s}$ \\
\hline Length & TBD & $\mathrm{m}$ \\
\hline Diameter: To & 2.50 & $\mathrm{~m}$ \\
\hline Diameter: From & 0.43 & $\mathrm{~m}$ \\
\hline Diameter: Average & 1.47 & $\mathrm{~m}$ \\
\hline \multicolumn{3}{|l|}{ Pipe to/from Industrial Process } \\
\hline Velocity Limit & 4 & $\mathrm{~m} / \mathrm{s}$ \\
\hline Length & TBD & $\mathrm{m}$ \\
\hline Diameter: To & 0.36 & $\mathrm{~m}$ \\
\hline Diameter: From & 0.06 & $\mathrm{~m}$ \\
\hline Diameter: Average & 0.21 & $\mathrm{~m}$ \\
\hline \multicolumn{3}{|l|}{ Sensors (outputs) } \\
\hline \multicolumn{3}{|l|}{ General } \\
\hline Inlet (from SG): Mass Flow Rate & 502.8 & $\mathrm{~kg} / \mathrm{s}$ \\
\hline Inlet (from SG): Pressure & $5.80 \mathrm{E}+06$ & $\mathrm{~Pa}$ \\
\hline Inlet (from SG): Temperature & 591 & $\mathrm{~K}$ \\
\hline Outlet (to ST): Mass Flow Rate & 492.8 & $\mathrm{~kg} / \mathrm{s}$ \\
\hline Outlet (to ST): Pressure & $5.80 \mathrm{E}+06$ & $\mathrm{~Pa}$ \\
\hline Outlet (to ST): Temperature & 591 & $\mathrm{~K}$ \\
\hline Outlet (to IP): Mass Flow Rate & 10 & $\mathrm{~kg} / \mathrm{s}$ \\
\hline Outlet (to IP): Pressure & $5.80 \mathrm{E}+06$ & $\mathrm{~Pa}$ \\
\hline Outlet (to IP): Temperature & 591 & $\mathrm{~K}$ \\
\hline Inlet (from ST): Mass Flow Rate & 492.8 & $\mathrm{~kg} / \mathrm{s}$ \\
\hline Inlet (from ST): Pressure & $6.27 \mathrm{E}+06$ & $\mathrm{~Pa}$ \\
\hline Inlet (from ST): Temperature & 497 & $\mathrm{~K}$ \\
\hline
\end{tabular}


Table 2. Manifold sensor and control signals (continued)

\begin{tabular}{|c|c|c|}
\hline Variable/Measurement & Value & Unit(s) \\
\hline \multicolumn{3}{|c|}{ Parameters (variables) } \\
\hline \multicolumn{3}{|c|}{ General } \\
\hline Inlet (from IP): Pressure & $6.27 \mathrm{E}+06$ & $\mathrm{~Pa}$ \\
\hline Inlet (from IP): Temperature & 497 & $\mathrm{~K}$ \\
\hline Outlet (to SG): Mass Flow Rate & 502.8 & $\mathrm{~kg} / \mathrm{s}$ \\
\hline Outlet (to SG): Pressure & $6.27 \mathrm{E}+06$ & $\mathrm{~Pa}$ \\
\hline Outlet (to SG): Temperature & 497 & $\mathrm{~K}$ \\
\hline \multicolumn{3}{|c|}{$\begin{array}{ll}\text { Splitter (All steam) } \\
\end{array}$} \\
\hline Pressure & $5.80 \mathrm{E}+06$ & $\mathrm{~Pa}$ \\
\hline Temperature & 591 & $\mathrm{~K}$ \\
\hline \multicolumn{3}{|c|}{ Mixer (All liquid) } \\
\hline Pressure & $6.27 \mathrm{E}+06$ & $\mathrm{~Pa}$ \\
\hline Temperature & 497 & $\mathrm{~K}$ \\
\hline \multicolumn{3}{|c|}{ Controls (inputs) } \\
\hline \multicolumn{3}{|c|}{ Steam Turbine Distribution Valve (STDV) } \\
\hline Valve Position & 50 & $\%$ \\
\hline \multicolumn{3}{|c|}{ Industrial Process Distribution Valve (IPDV) } \\
\hline Valve Position & 50 & $\%$ \\
\hline
\end{tabular}

The "Valve Position" control for both the steam turbine distribution valve (STDV) and the Industrial process distribution valve (IPDV) do not necessarily sum to 100\% (although they do in this example.) The STDV and IPDV are sized independently such that the mass flow at $100 \%$ valve position for the STDV does not necessarily correspond to the mass flow at 100\% valve position for the IPDV. In this example, the STDV is sized "large" and the IPDV is sized "small;" this indicates that $100 \%$ flow through the STDV is greater than 100\% flow through the IPDV. Additionally, the turbine instrumentation and control must account for the requirement to maintain motion to avoid bearing damage.

\subsection{POWER CONVERSION SYSTEM}

Thermal energy from the manifold to the steam turbine is converted to electrical energy within a simplified representation of a combined high-pressure and low-pressure turbine system. Waste heat is rejected to the atmosphere. Fig. 3 shows the balance of plant with its connections to the manifold, the atmosphere, and the switch yard. 


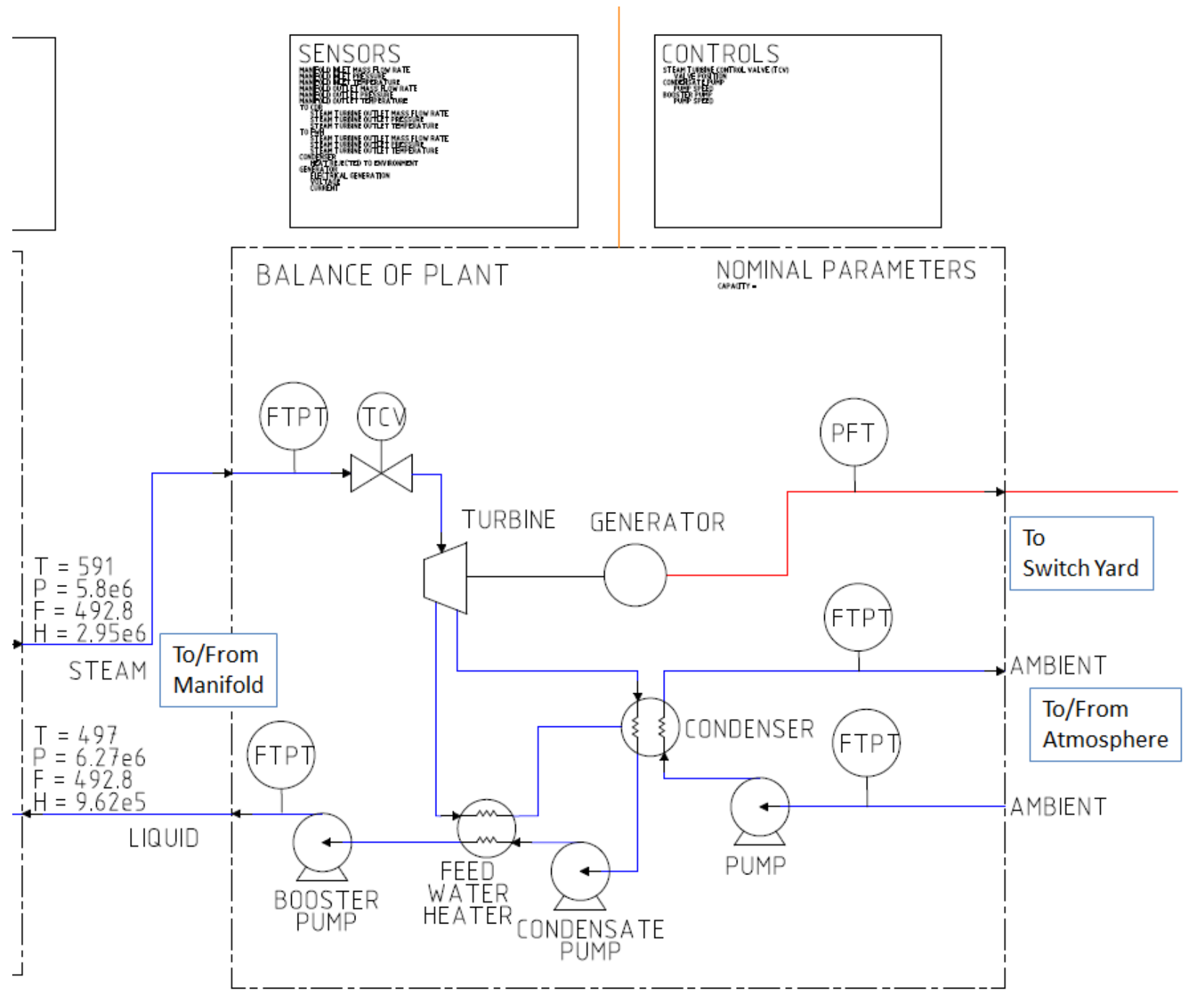

Fig. 3. Nuclear Hybrid Energy Systems balance of plant model.

The parameters (variables), sensors (outputs), and controls (inputs) for the manifold are given in Table 3 with nominal values. 
Table 3. Balance of plant sensor and control signals

\begin{tabular}{|c|c|c|}
\hline Variable/Measurement & Value & Unit(s) \\
\hline \multicolumn{3}{|c|}{ Parameters (variables) } \\
\hline \multicolumn{3}{|l|}{ Steam Turbine } \\
\hline Nominal Capacity & $980 \mathrm{E}+06$ & $\mathrm{~W}$ \\
\hline \multicolumn{3}{|l|}{ Sensors (outputs) } \\
\hline \multicolumn{3}{|l|}{ General } \\
\hline Inlet (from Manifold): Mass Flow Rate & 492.8 & $\mathrm{~kg} / \mathrm{s}$ \\
\hline Inlet (from Manifold): Pressure & $5.80 \mathrm{E}+06$ & $\mathrm{~Pa}$ \\
\hline Inlet (from Manifold): Temperature & 591 & $\mathrm{~K}$ \\
\hline Outlet (to Manifold): Mass Flow Rate & 492.8 & $\mathrm{~kg} / \mathrm{s}$ \\
\hline Outlet (to Manifold): Pressure & $6.27 \mathrm{E}+06$ & $\mathrm{~Pa}$ \\
\hline Outlet (to Manifold): Temperature & 497 & $\mathrm{~K}$ \\
\hline \multicolumn{3}{|l|}{ Steam Turbine } \\
\hline Outlet (to CDR): Mass Flow Rate & 492.8 & $\mathrm{~kg} / \mathrm{s}$ \\
\hline Outlet (to CDR): Pressure & $5.80 \mathrm{E}+06$ & $\mathrm{~Pa}$ \\
\hline Outlet (to CDR): Temperature & 591 & $\mathrm{~K}$ \\
\hline Outlet (to FWH): Mass Flow Rate & 492.8 & $\mathrm{~kg} / \mathrm{s}$ \\
\hline Outlet (to FWH): Pressure & $<5.8 \mathrm{e} 6$ & $\mathrm{~Pa}$ \\
\hline Outlet (to FWH): Temperature & $<497$ & $\mathrm{~K}$ \\
\hline \multicolumn{3}{|l|}{ Condenser } \\
\hline Heat Rejected to Environment & TBD & $\mathrm{W}$ \\
\hline \multicolumn{3}{|l|}{ Generator } \\
\hline Electrical Generation & $980 \mathrm{E}+06$ & $\mathrm{~W}$ \\
\hline Voltage & $11 \mathrm{kV}$ & $\mathrm{V}$ \\
\hline Current & $\sim 90 \mathrm{kA}$ & A \\
\hline Frequency & $50 / 60$ & $\mathrm{~Hz}$ \\
\hline \multicolumn{3}{|l|}{ Controls (inputs) } \\
\hline \multicolumn{3}{|c|}{ Steam Turbine Control Valve (STCV) } \\
\hline Valve Position & 50 & $\%$ \\
\hline \multicolumn{3}{|l|}{ Pumps } \\
\hline Condensate Pump Speed & 1500 & RPM \\
\hline Booster Pump Speed & 1500 & RPM \\
\hline
\end{tabular}

Electricity from the generator is directed to a switch yard. The switch yard also receives electricity from the gas turbine and the battery in this NHES configuration. The switch yard also directs electricity to the battery for charging, the hydrogen production plant for use, or to the grid. Fig. 4 shows the switch yard with its connections. 


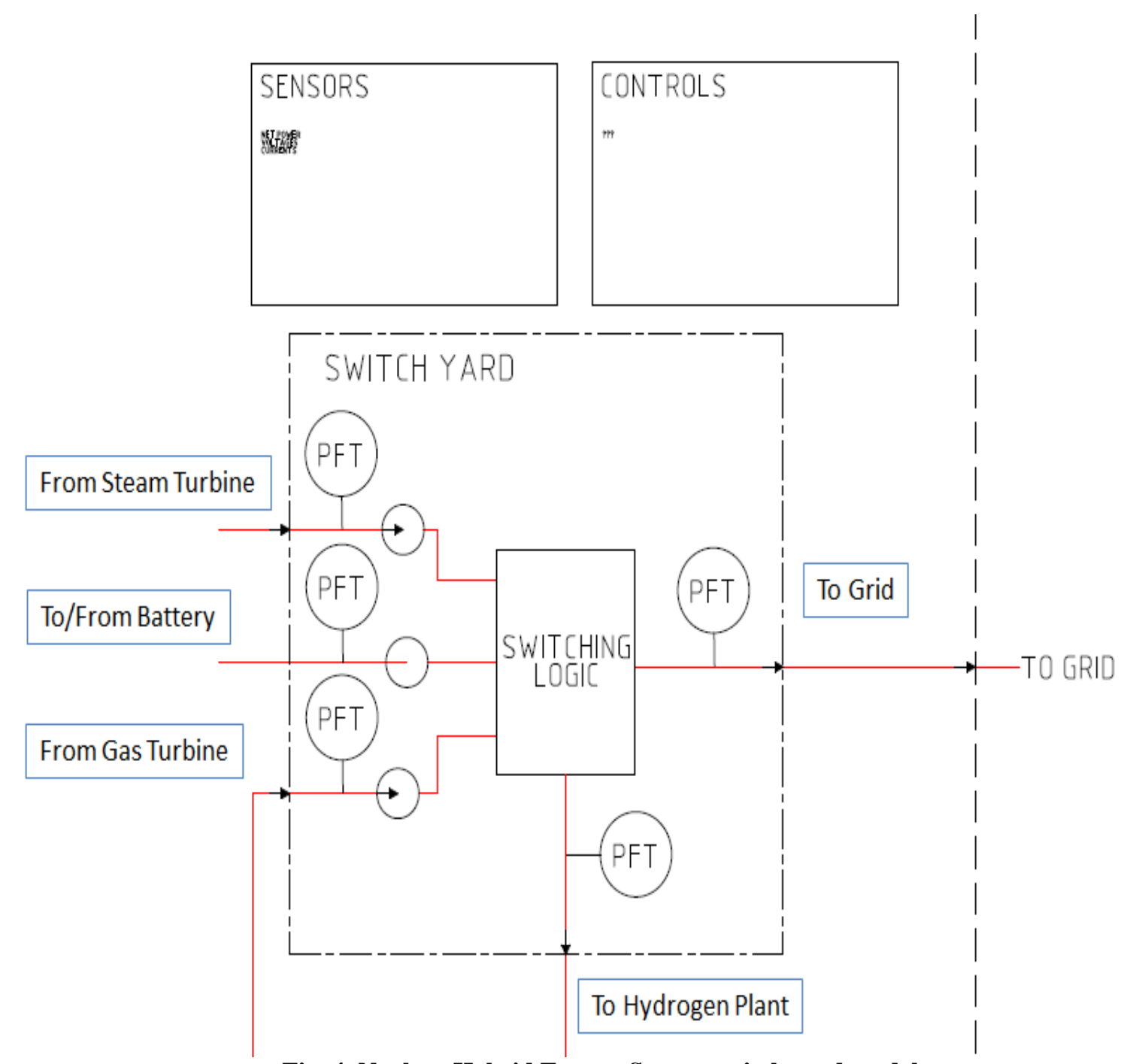

Fig. 4. Nuclear Hybrid Energy System switch yard model.

The parameters (variables), sensors (outputs), and controls (inputs) for the switch yard are given in Table 4 with nominal values. 
Table 4. Switch yard sensor and control signals

\begin{tabular}{|c|c|c|}
\hline Variable/Measurement & Value & Unit(s) \\
\hline \multicolumn{3}{|c|}{ Parameters (variables) } \\
\hline TBD & TBD & TBD \\
\hline \multicolumn{3}{|c|}{ Sensors (outputs) } \\
\hline \multicolumn{3}{|c|}{ Steam Turbine } \\
\hline Power & 980MW & $\mathrm{W}$ \\
\hline Voltage & $11 \mathrm{kV}$ & $\mathrm{V}$ \\
\hline Current & $90 \mathrm{kA}$ & A \\
\hline Frequency & $60 \mathrm{~Hz}$ & $\mathrm{~Hz}$ \\
\hline \multicolumn{3}{|c|}{ Gas Turbine } \\
\hline Power & 44MW & $\mathrm{W}$ \\
\hline Voltage & $11 \mathrm{kV}$ & $\mathrm{V}$ \\
\hline Current & $4 \mathrm{kA}$ & A \\
\hline Frequency & $60 \mathrm{~Hz}$ & $\mathrm{~Hz}$ \\
\hline \multicolumn{3}{|l|}{ Battery } \\
\hline Power & 100MWh & W-hour \\
\hline Voltage & $11 \mathrm{kV}$ & $\mathrm{V}$ \\
\hline Current & $9.1 \mathrm{kA}$ & A \\
\hline Frequency & 60 & $\mathrm{~Hz}$ \\
\hline \multicolumn{3}{|l|}{ Industrial Process } \\
\hline Power & TBD & $\mathrm{W}$ \\
\hline Voltage & TBD & $\mathrm{V}$ \\
\hline Current & TBD & A \\
\hline Frequency & TBD & $\mathrm{Hz}$ \\
\hline \multicolumn{3}{|l|}{ Grid } \\
\hline Power & TBD & $\mathrm{W}$ \\
\hline Voltage & TBD & $\mathrm{V}$ \\
\hline Current & TBD & A \\
\hline Frequency & TBD & $\mathrm{Hz}$ \\
\hline \multicolumn{3}{|l|}{ Controls (inputs) } \\
\hline TBD & TBD & TBD \\
\hline
\end{tabular}

\subsection{ELECTRICAL STORAGE SYSTEM}

The storage battery charges and discharges through its connection to the switch yard. Fig. 5 shows the storage battery with its connection to the switch yard. The storage battery model is generated and maintained by ANL. 


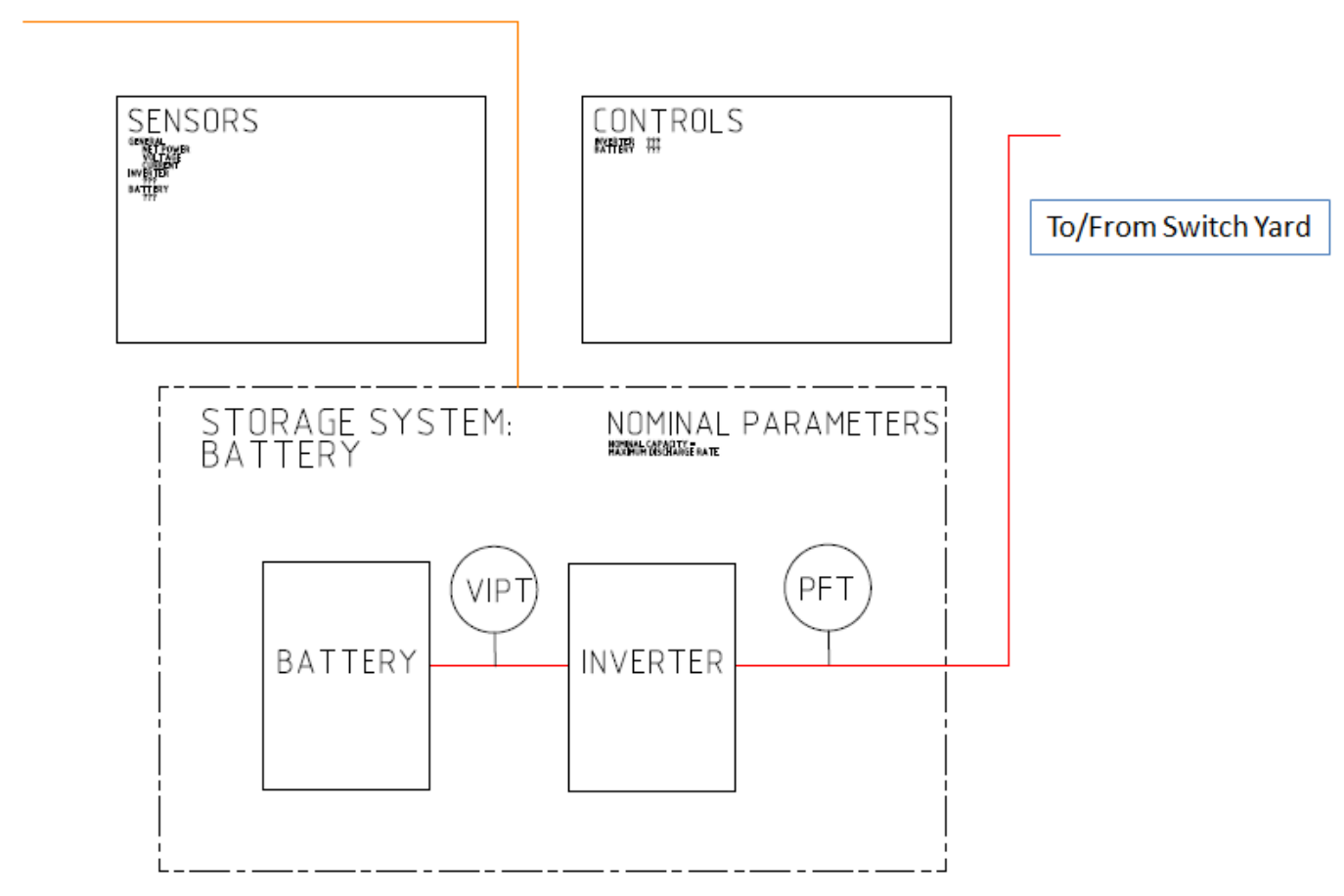

Fig. 5. Nuclear Hybrid Energy Systems battery system model.

The parameters (variables), sensors (outputs), and controls (inputs) for the battery are given in Table 5 with nominal values.

Table 5. Storage battery system sensor and control signals

\begin{tabular}{|l|c|c|}
\hline \multicolumn{1}{|c|}{ Variable/Measurement } & Value & Unit(s) \\
\hline \multicolumn{3}{|c|}{ Parameters (variables) } \\
\hline Nominal Capacity & TBD & Wh \\
\hline Maximum Charge/Discharge Rate & TBD & W \\
\hline \multicolumn{3}{|c|}{ Sensors (outputs) } \\
\hline General \\
\hline Power & TBD & W \\
\hline Voltage & TBD & V \\
\hline Current & TBD & A \\
\hline Frequency & TBD & Hz \\
\hline \multicolumn{4}{|c|}{ Inverter } & TBD & TBD \\
\hline TBD & Battery \\
\hline \multicolumn{4}{|c|}{} & TBD & TBD \\
\hline TBD & TBD & TBD \\
\hline \multicolumn{4}{|c|}{}
\end{tabular}




\subsection{AUXILIARY POWER GENERATION SYSTEM}

The gas turbine acts as a backstop for power generation. It receives natural gas as a supply, discharges waste heat to the atmosphere, and supplies electricity to the switch yard using an open Brayton cycle. Fig. 6 shows the gas turbine with its connections to the switch yard, the atmosphere, and the gas supply.

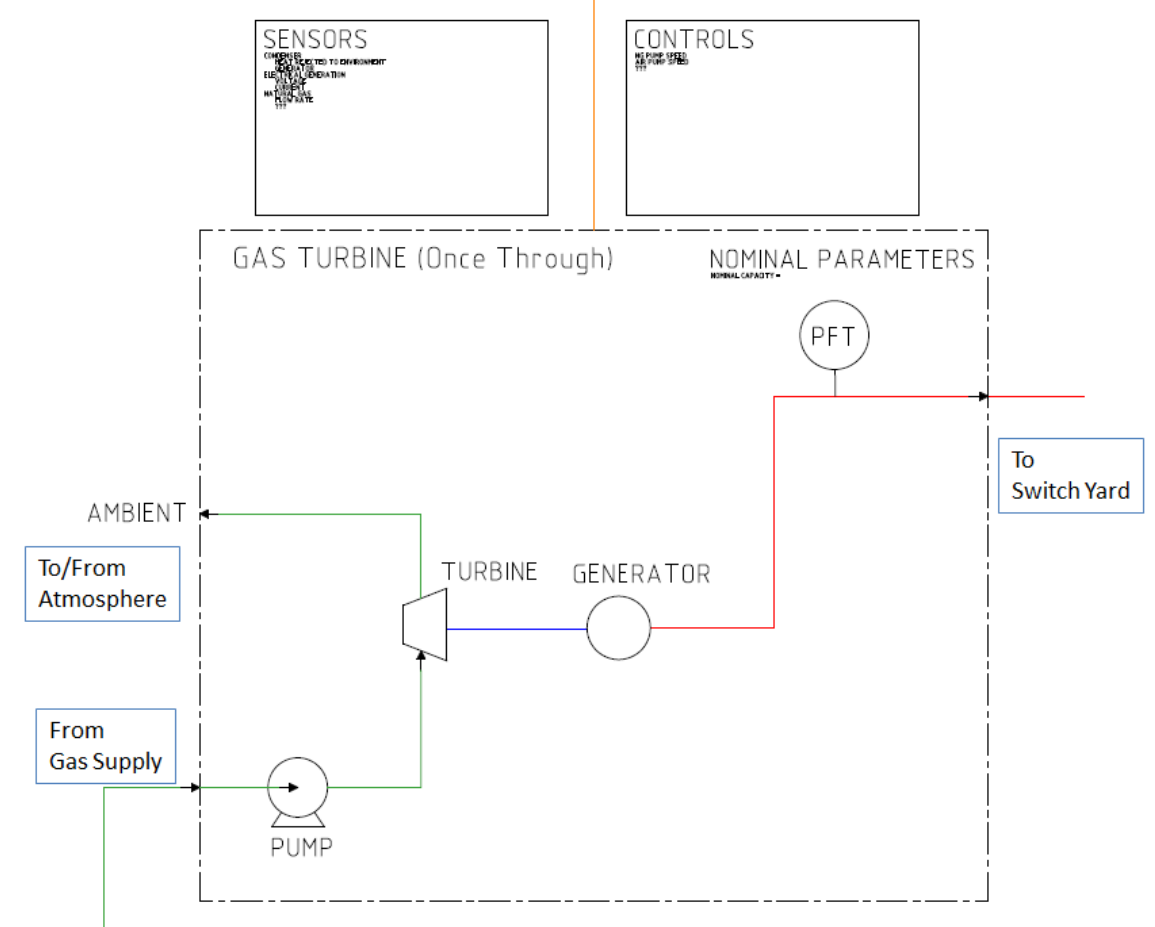

Fig. 6. Nuclear Hybrid Energy System gas turbine model.

The parameters (variables), sensors (outputs), and controls (inputs) for the gas turbine are given in Table 6 with nominal values.

Table 6. Gas turbine sensor and control signals

\begin{tabular}{|c|c|c|}
\hline Variable/Measurement & Value & Unit(s) \\
\hline \multicolumn{3}{|c|}{ Parameters (variables) } \\
\hline Nominal Capacity & TBD & $\mathrm{W}$ \\
\hline \multicolumn{3}{|c|}{ Sensors (outputs) } \\
\hline \multicolumn{3}{|c|}{ Generator } \\
\hline Power & TBD & $\mathrm{W}$ \\
\hline Voltage & TBD & $\mathrm{V}$ \\
\hline Current & TBD & A \\
\hline Frequency & TBD & $\mathrm{Hz}$ \\
\hline \multicolumn{3}{|c|}{ Natural Gas } \\
\hline Flow Rate & TBD & $\mathrm{kg} / \mathrm{s}$ \\
\hline \multicolumn{3}{|c|}{ Controls (inputs) } \\
\hline Natural Gas Pump Speed & TBD & RPM \\
\hline Air Pump Speed & TBD & RPM \\
\hline
\end{tabular}




\subsection{INDUSTRIAL CUSTOMER}

The hydrogen production plant receives thermal power from the manifold and electrical power from the switch yard. The hydrogen production plant is situated at some standoff distance from the manifold; this distance will have some effect on the actual power delivered to the hydrogen plant from the manifold (e.g., time delays and heat dissipation). It discharges waste heat to the atmosphere and sends hydrogen to the market. Fig. 7 shows the hydrogen production plant and its connections to the manifold, switch yard, atmosphere, and market. The hydrogen production plant model is generated and maintained by INL.

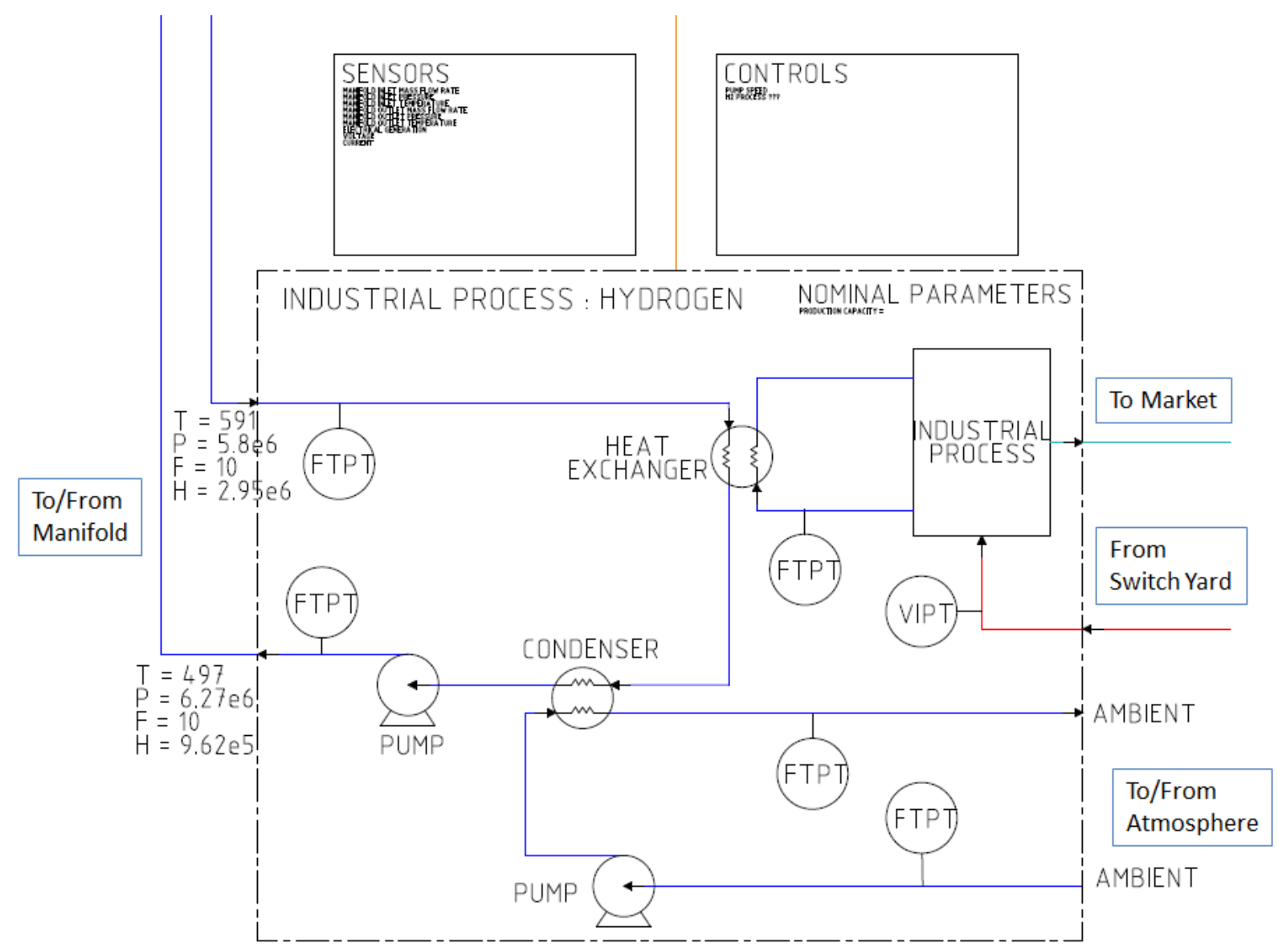

Fig. 7. Nuclear Hybrid Energy System hydrogen production plant model.

The parameters (variables), sensors (outputs), and controls (inputs) for the hydrogen production plant are given in Table 7 with nominal values. 
Table 7. Hydrogen production plant sensor and control signals

\begin{tabular}{|c|c|c|}
\hline Variable/Measurement & Value & Units \\
\hline \multicolumn{3}{|c|}{ Parameters (variables) } \\
\hline Nominal Capacity & TBD & $\mathrm{kg} / \mathrm{s}$ \\
\hline \multicolumn{3}{|l|}{ Sensors (outputs) } \\
\hline \multicolumn{3}{|l|}{ General } \\
\hline Inlet (from Manifold): Mass Flow Rate & 10 & $\mathrm{~kg} / \mathrm{s}$ \\
\hline Inlet (from Manifold): Pressure & $5.80 \mathrm{E}+06$ & $\mathrm{~Pa}$ \\
\hline Inlet (from Manifold): Temperature & 591 & $\mathrm{~K}$ \\
\hline Outlet (to Manifold): Mass Flow Rate & 10 & $\mathrm{~kg} / \mathrm{s}$ \\
\hline Outlet (to Manifold): Pressure & $6.27 \mathrm{E}+06$ & $\mathrm{~Pa}$ \\
\hline Outlet (to Manifold): Temperature & 497 & $\mathrm{~K}$ \\
\hline Electrical Consumption & TBD & $\mathrm{W}$ \\
\hline Voltage & TBD & $\mathrm{V}$ \\
\hline Current & TBD & A \\
\hline \multicolumn{3}{|l|}{ Condenser } \\
\hline Heat Rejection & TBD & $\mathrm{W}$ \\
\hline \multicolumn{3}{|l|}{ Controls (inputs) } \\
\hline Condensate Pump Speed & 1500 & RPM \\
\hline
\end{tabular}





\section{MODELING THE NUCLEAR HYBRID ENERGY SYSTEM}

\subsection{MODELING METHODOLOGY}

The modeling of a nuclear hybrid energy system is a multi-domain problem requiring modeling complex physical problems such as those dealing with electrical, thermal hydraulic, and control systems. Further, the optimization of the overall system requires analyzing the full design space of the input parameters given above. This optimization over the parameter space will be performed using RAVEN [4] as the parametric input driver. RAVEN will feed input parameters to the system model and analyze output from the system model to drive its optimization algorithm. This process will be developed and controlled by INL.

All modeling activities, outside of RAVEN, are performed using the open source, equation based Modelica programming language within the Dymola development environment. The development of all models using Modelica allows key benefits such the direct compatibility of independently developed models. No additional software interfaces or other manipulation is required.

\subsubsection{Modelica}

Modelica is a domain neutral programming language and is therefore flexible in the types of problems it can evaluate. Modelica is also an equation based language (not necessary to have causal equation relationships) designed specifically to evaluate dynamic problems. As a dynamic modeling language, the programmer/user does not explicitly code in time dependencies of variables, but defines the relation and interaction among the time dependent variables which are then solved by integrated numerical solvers.

Another important aspect of the Modelica language is its hierarchal development design. Proper model development allows development of common submodels that can gradually be "extended" to allow for more complex models without changing the lower level submodels. This structure allows for a more intuitive general model development where components, closure models (e.g., heat transfer correlations and pressure drop correlations), and even the working media (e.g., water, steam, molten salts, gases) can be readily replaced without any modification to the system or source code.

\subsection{NUCLEAR STEAM SUPPLY SYSTEM MODEL}

The nuclear steam supply system (NSSS) is based on the International Reactor Innovative and Secure (IRIS) integral pressurized light water medium power (1000 MWt) reactor design. The IRIS design was developed by an international consortium led by Westinghouse Electric Co. Originally sponsored by the Department of Energy as part of the Nuclear Energy Research Initiative program, IRIS was subsequently selected as an International Near Term Deployment reactor within the Generation IV International Forum activities [5]. Given the relative maturity of the design and amount of quality publically available information, the IRIS reactor was deemed an appropriate choice for development of a dynamic system model. However, there were discrepancies in the literature among some of the nominal parameters. Table 8 summarizes the nominal IRIS system operating parameters that were used in the current model. Fig. 8 is the Modelica IRIS NSSS model. 
Table 8. International Reactor Innovative and Secure design parameters for the nuclear steam supply system

\begin{tabular}{lcc}
\hline \multicolumn{1}{c}{ Parameter } & Value & Unit \\
\hline Core thermal power & 1000 & $\mathrm{MWt}$ \\
Primary coolant flow rate & 4700 & $\mathrm{~kg} / \mathrm{s}$ \\
Reactor operating pressure & 15.5 & $\mathrm{MPa}$ \\
Core inlet coolant temperature & 283 & ${ }^{\circ} \mathrm{C}$ \\
Core outlet coolant temperature & 321 & ${ }^{\circ} \mathrm{C}$ \\
Core temperature rise & 38 & ${ }^{\circ} \mathrm{C}$ \\
Number of steam generators & 8 & \\
Steam generator thermal capacity & 125 & $\mathrm{MWt}$ \\
Total steam generator flow rate & 502.8 & $\mathrm{~kg} / \mathrm{s}$ \\
Steam generator inlet pressure & 6.27 & $\mathrm{MP}$ \\
Steam generator outlet pressure & 5.8 & $\mathrm{MPa}$ \\
Steam generator inlet temperature & 224 & ${ }^{\circ} \mathrm{C}$ \\
Steam generator outlet temperature & 318 & ${ }^{\circ} \mathrm{C}$ \\
\hline
\end{tabular}

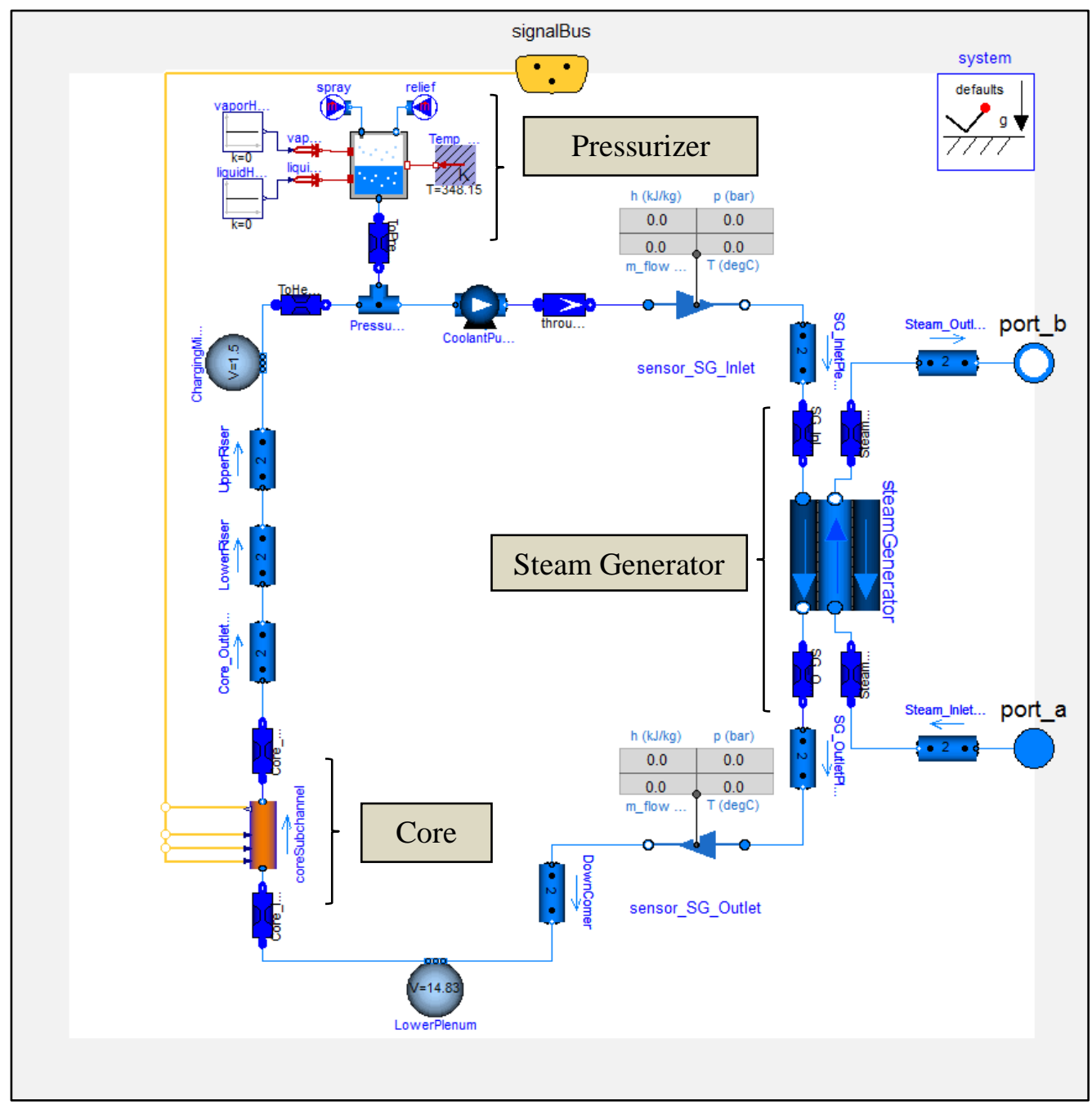

Fig. 8. Modelica model of the International Reactor Innovative and Secure nuclear steam supply system. 
In the published literature there are three primary components to the IRIS NSSS model that have received special attention that are included in the current iteration of the NSSS design: the nuclear reactor core, the pressurizer, and the helical coil steam generator. Each of these components is labeled in Fig. 8.

\subsubsection{Nuclear Reactor Core}

The IRIS core and fuel characteristics are similar to those of a conventional Westinghouse PWR design. Design parameters of the reactor core are summarized in Table 9 [5] [6].

Table 9. Summary of design parameters for the International Reactor Innovative and Secure $1000 \mathrm{MWt}$ nuclear reactor core

\begin{tabular}{lcc}
\hline \multicolumn{1}{c}{ Parameter } & Value & Unit \\
\hline Core thermal power & 1000 & $\mathrm{MWt}$ \\
Active core height & 2.47 & $\mathrm{M}$ \\
Number of fuel assemblies & 89 & \\
Rod array & $17 \times 17$ & square \\
Number of fuel rods/assembly & 264 & \\
Outer diameter of fuel rods (cladding) & 9.5 & $\mathrm{~mm}$ \\
Total flow area & 2.73 & $\mathrm{~m}^{2}$ \\
Fuel type: sintered $\mathrm{UO}_{2}$ pellets & $\sim 5 \%$ & \\
Average linear heat rate & 10 & $\mathrm{~kW} / \mathrm{m}$ \\
\hline
\end{tabular}

The Modelica model of the reactor core accounts for important physical behaviors including material behavior, heat transfer and pressure drop closure models, geometry, and reactor kinetics. Each of these attributes have been incorporated by constructing the fuel model from generic lower models that are linked together to create a fuel subchannel or core model. Fig. 9 shows the actual depiction of the models incorporated into the core model.
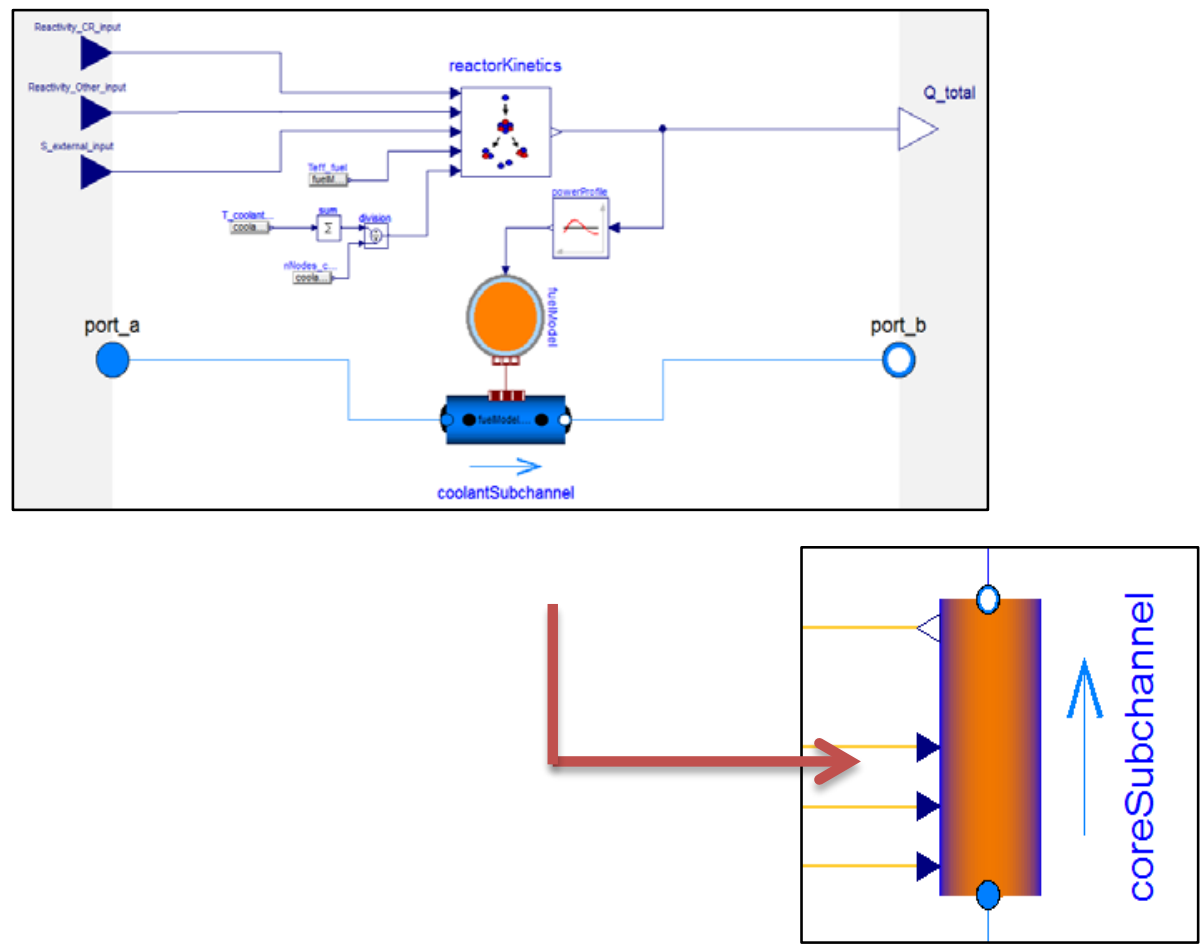

Fig. 9. Demonstration of linked lower level models. 


\subsubsection{Internal Pressurizer}

The pressurizer for IRIS is located in the upper head (inside the pressure vessel), above the internal control rod mechanisms yielding (FEFE). Additional details on the design can be found in the following literature: [7], [8], and [9]. One key aspect of the IRIS pressurizer illustrated in Fig. 10 is its ability to mitigate pressurization transients. It has been designed so that no active spray/heating system is required during power operation; they are only operated during plant shutdown.

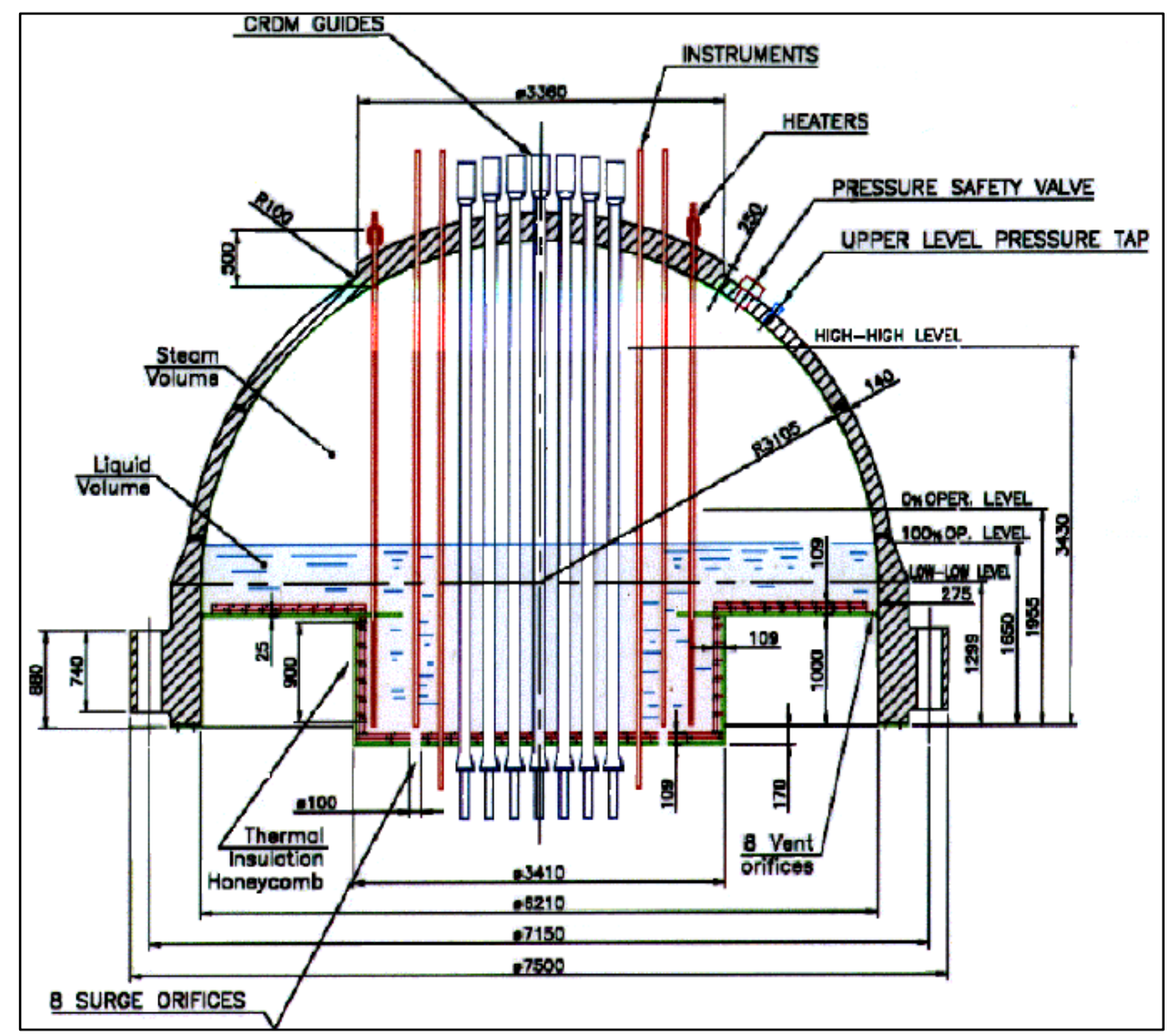

Fig. 10. Design drawing of the International Reactor Innovative and Secure pressurizer [7].

The Modelica model accounts for the primary physical behaviors observed in pressurizers and the pressurizer's unique geometry. The model is a lumped pressure approach where the vapor and liquid phases are at the same pressure but are not necessarily in thermodynamic equilibrium. Closure models (e.g., liquid surface and mass transfer) have been made replaceable in their implementation so that, as necessary, appropriate levels of complexity can be incorporated to more accurately capture the real behavior of the pressurizer under all investigated scenarios (Fig. 11). 


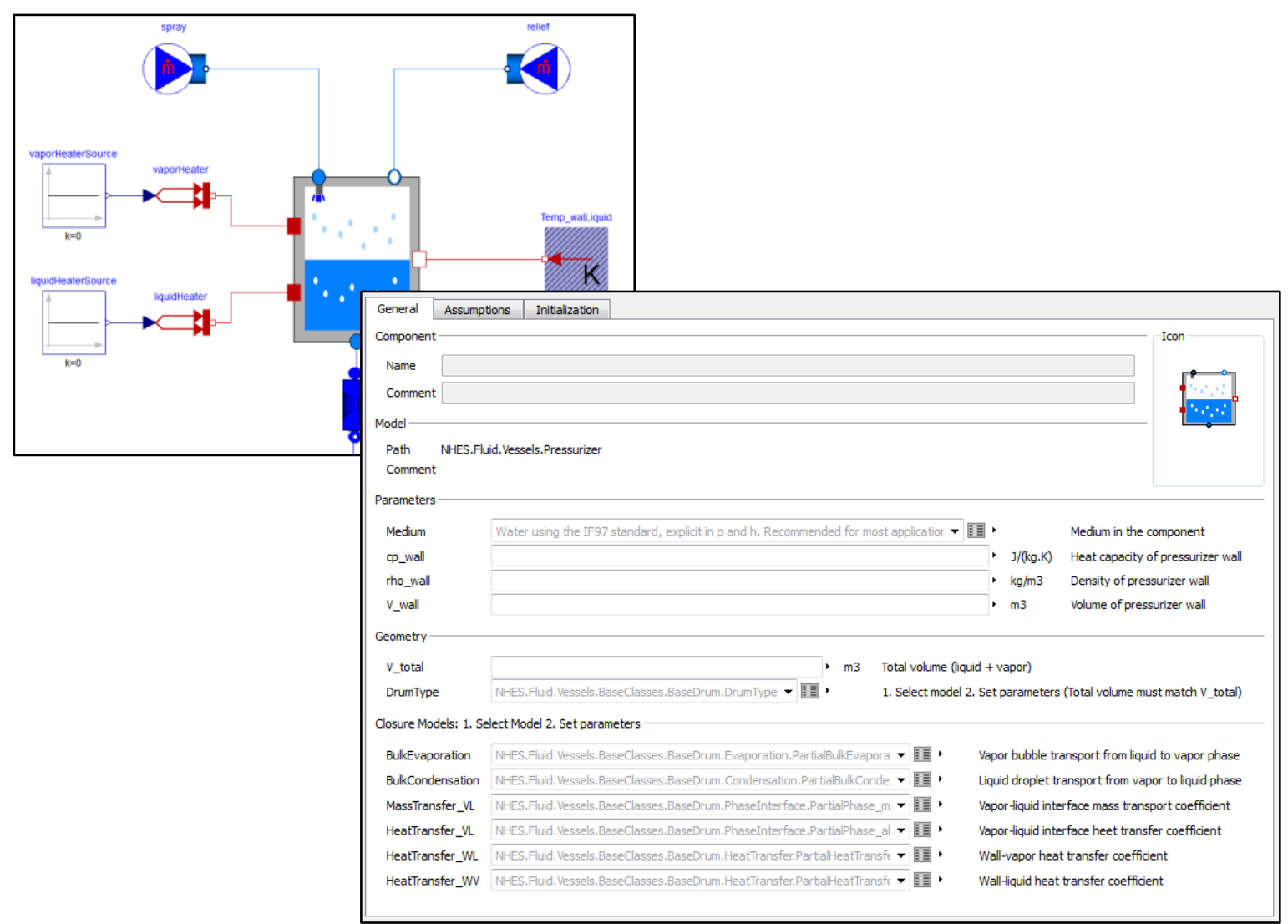

Fig. 11. Modelica pressurizer model (left) and user definable parameters (right).

\subsubsection{Helical Coil Steam Generator}

The steam generator is integral to the pressure vessel and consists of eight once-through coiled tubes located in the annular space between the core barrel and the reactor vessel wall. The secondary fluid boils within the tubes while the reactor cooling water provides cross flow through the tube bundle as the primary fluid and remains in a single phase state [10]. General design parameters are presented in Table 10.

Table 10. Design parameters for the International Reactor Innovative and Secure helical coil steam generator

\begin{tabular}{lcc}
\hline \multicolumn{1}{c}{ Parameter } & Value & Unit \\
\hline Thermal rating/steam generator & 125 & $\mathrm{MWt}$ \\
Mass flowrate/steam generator & 62.85 & $\mathrm{~kg} / \mathrm{s}$ \\
Steam tube outer diameter & 17.46 & $\mathrm{~mm}$ \\
Steam tube length & 32 & $\mathrm{~m}$ \\
Steam generator length & 7.9 & $\mathrm{~m}$ \\
\hline
\end{tabular}

Fig. 12 and Fig. 13 present the thermal behavior of the steam generator under design boundary conditions and a comparison to the results of [10]. The behavior of the model matches that presented by [10]. 


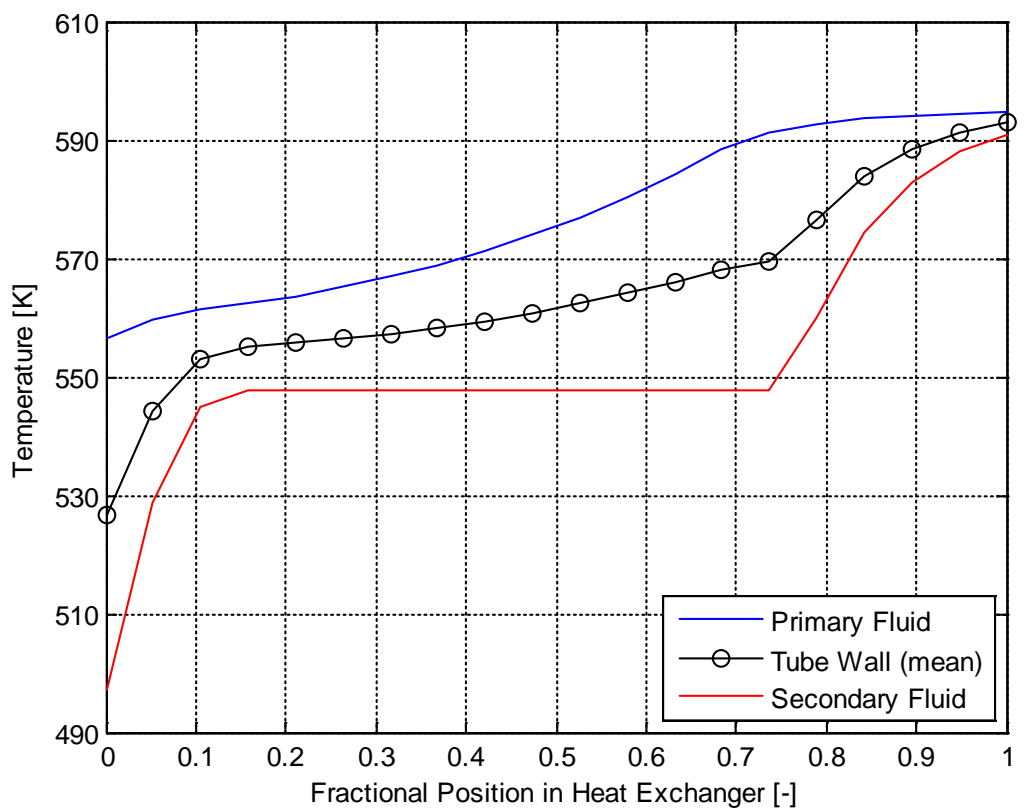

Fig. 12. Steam generation temperature by normalized axial height.

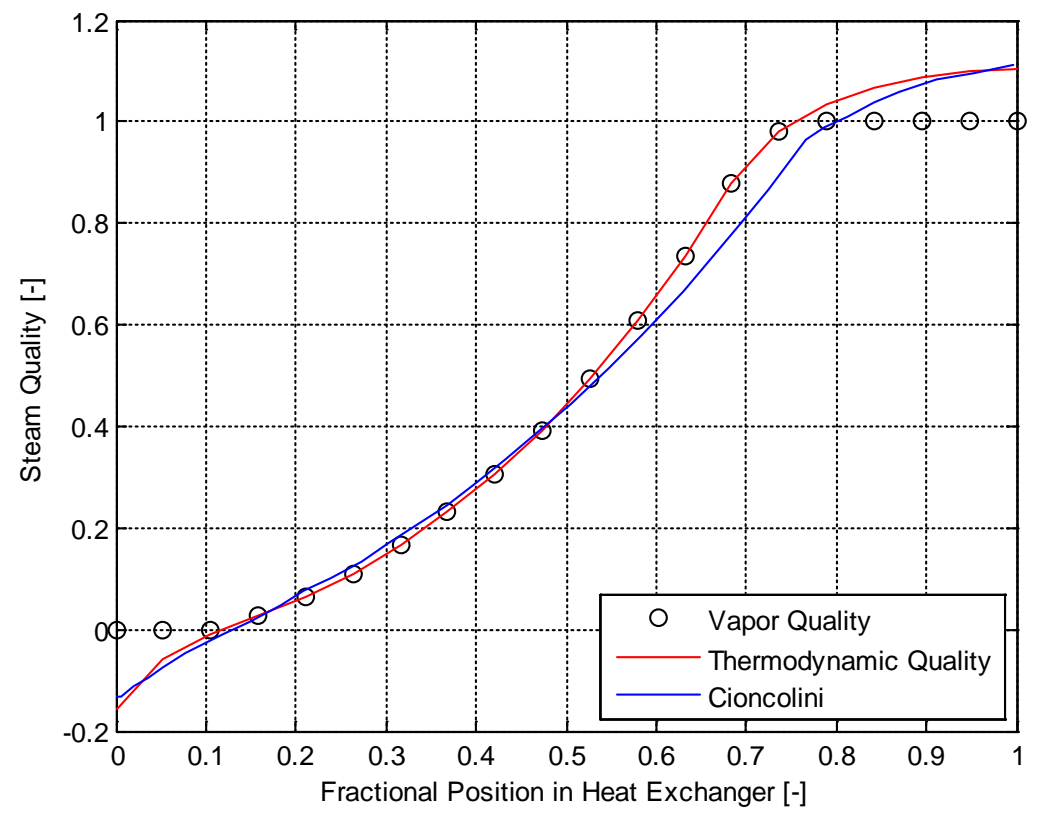

Fig. 13. Steam quality by normalized height compared to [10].

\subsection{THERMAL MANIFOLD MODEL}

The thermal manifold is the interface subsystem between the NSSS and other subsystem. As illustrated in Fig. 14, the name "manifold" is used because the role of the component is to distribute heat from the NSSS among multiple subsystems. 


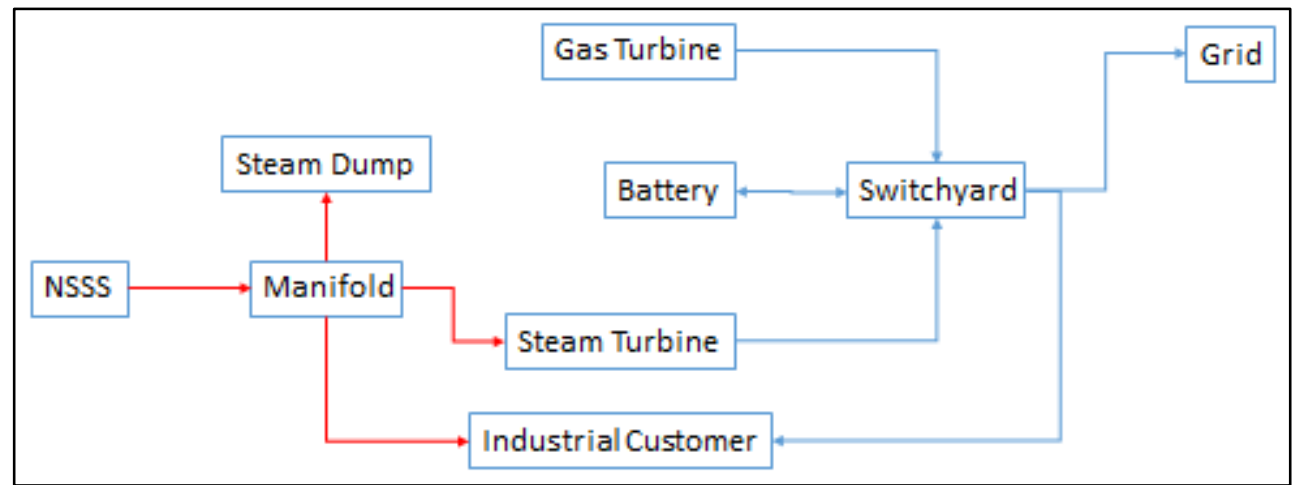

Fig. 14. Block diagram of the thermal manifold connections.

The initial thermal manifold that will be considered is a steam manifold. This manifold consists of a valve system that switches flow between subsystems based on demand signals (Fig. 15). However, it is possible that this type of thermal manifold will be insufficient in mitigating propagation of dynamics from the non-nuclear subsystems back to the nuclear subsystem. This is a point of concern as current reactor operation would require insulation from external factors. Therefore, depending on the system behavior observed using the steam manifold, future manifold designs may seek to remove this dynamic feedback behavior through means such as large thermal inertias within the manifold subsystem that effectively behave as low-pass filters.

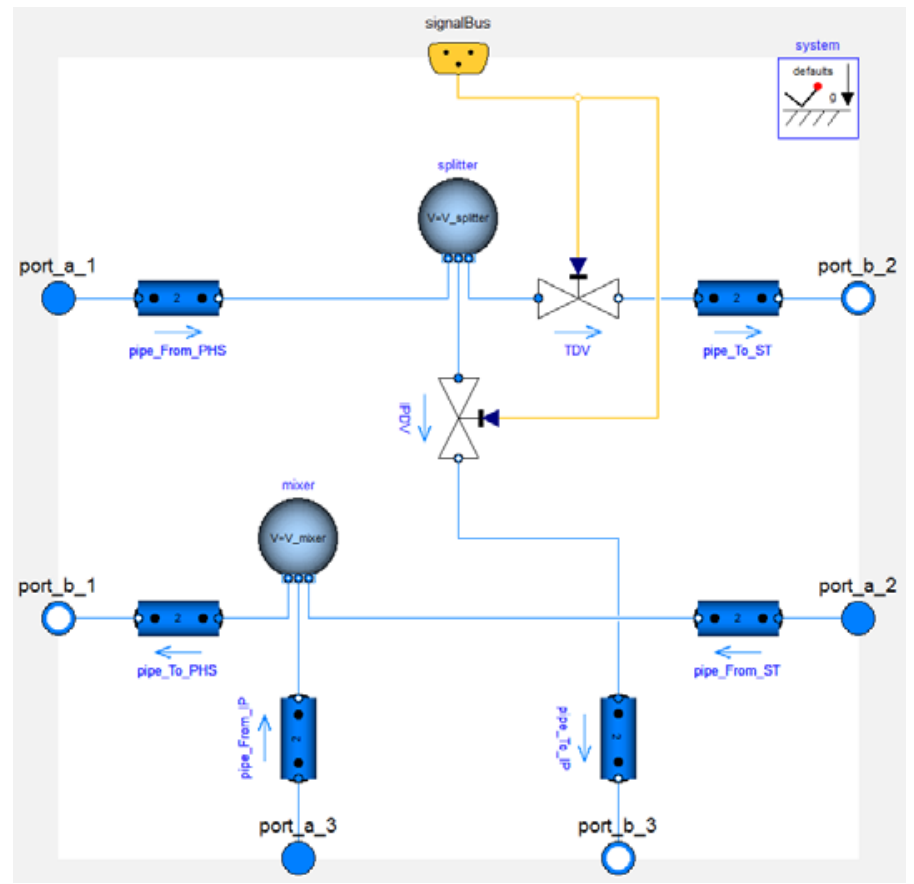

Fig. 15. Steam thermal manifold with valves and vessels to distribute flow.

\subsection{POWER CONVERSION SYSTEM MODEL}

The IRIS design planned for an 1800 RPM turbine system with a high pressure and low pressure turbine. [11] Typical plant designs include turbine controls, turbine steam valve controls, and condensate controls. 
Previous work for modeling ALMR concepts [12] included leveraging the use of various component model libraries. The ThermoPower open source library contains various base models for power conversion. [13]

Fig. 16 illustrates a high pressure turbine and a low pressure turbine system with a steam control valve on the steam flow input of the high pressure turbine. This steam turbine system model was based on the ThermoPower library with modifications for the proper IRIS capacity and dynamics. The steam turbine system model will be couples to an electrical generator model and grid model (Fig. 17) to add the capability to study the electrical generation and grid interactions.

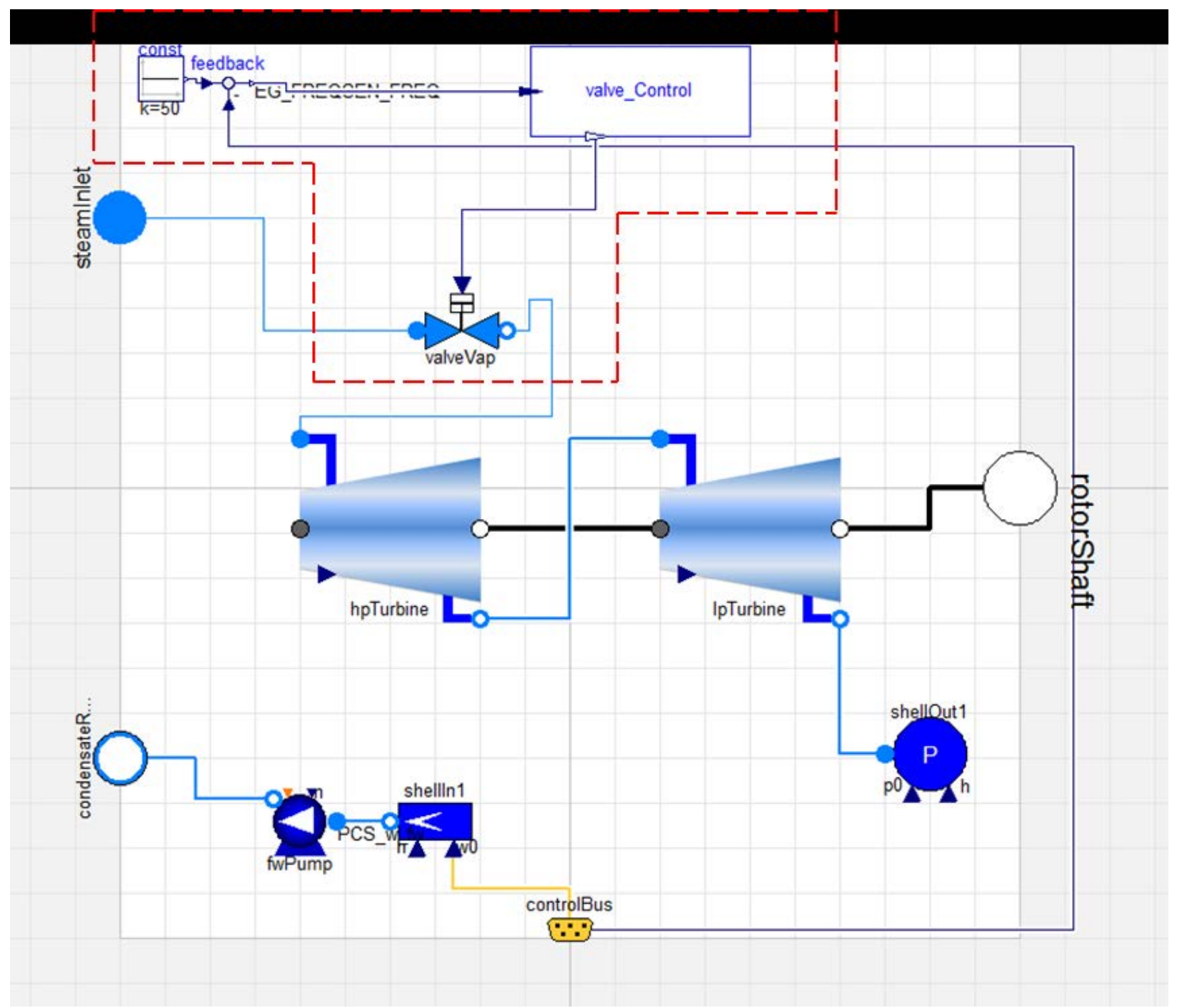

Fig. 16. Steam turbine power conversion system model. 


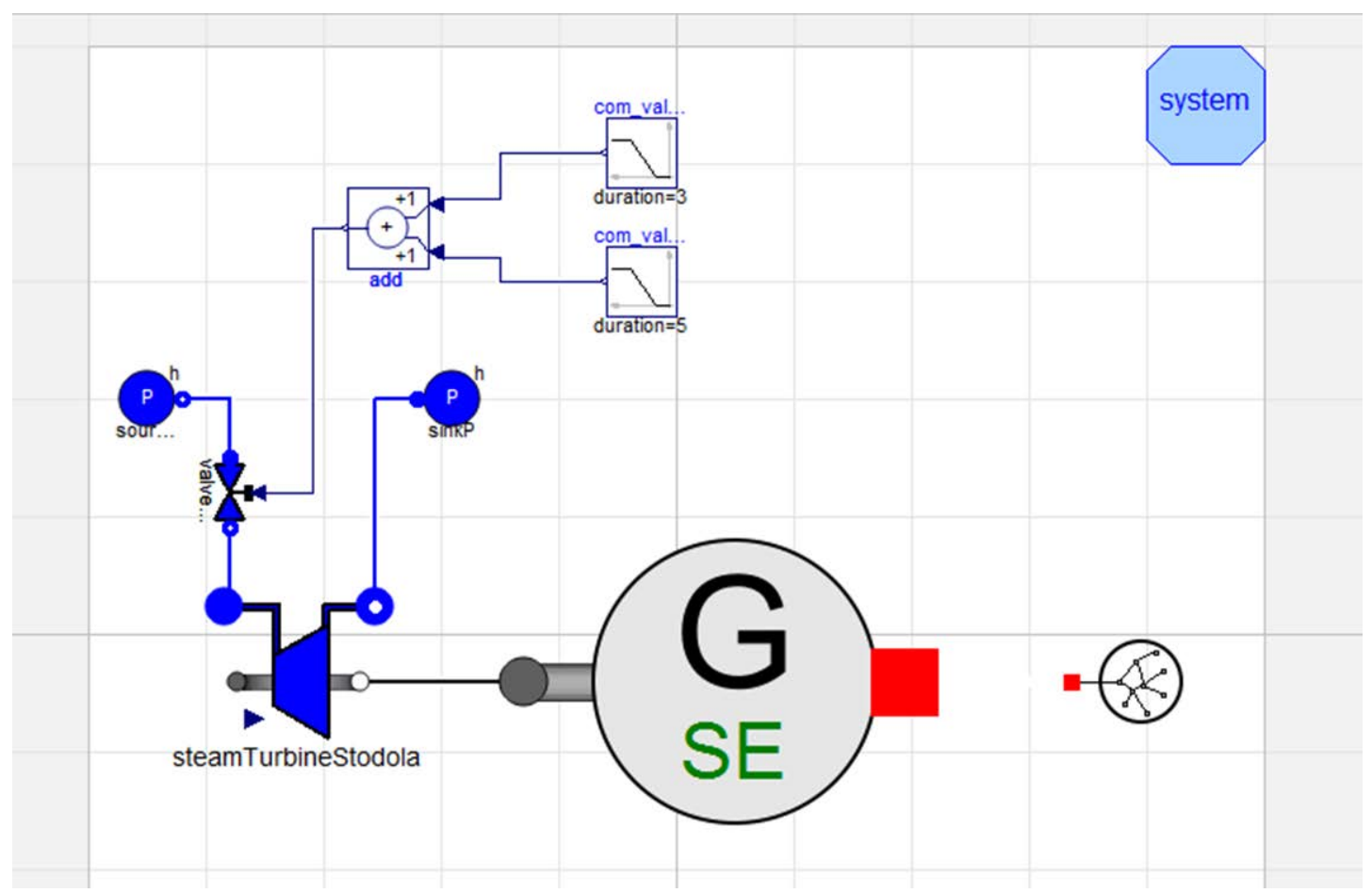

Fig. 17. Steam turbine with electrical generator system model.

\subsection{ELECTRICAL STORAGE SYSTEM MODEL}

The initial electrical storage subsystem consists of banks of batteries of types which are currently commercially available. The size of the storage system is then scaled according to the power storage demands of the system under investigation by varying the number of batteries connected in parallel. Important electrochemical behaviors will be included into the battery models such as discharge rates and lifetime limitations. The battery model will also be able to charge and discharge according to the demands of the supervisory control system. The battery model will be provided by ANL.

\subsection{INDUSTRIAL PROCESS MODEL}

A steam electrolysis hydrogen production plant is the initial industrial process to be included in the hybrid energy system investigation. Steam from the NSSS (via the thermal manifold) provides a portion of the process heat required. The steam will then be subcooled and sent back to the thermal manifold. The remainder of the power demands will be fulfilled by an electricity supply (i.e., steam generator, battery, gas turbine, grid). The hydrogen plant model will be provided by INL.

\subsection{AUXILIARY POWER GENERATION SYSTEM MODEL}

A natural gas turbine model will be included in the overall hybrid energy system. The gas turbine will cover rapid grid demands that the dynamics of the remainder of the hybrid system cannot handle. The gas turbine model will be provided by INL.

\subsection{SWITCH YARD MODEL}

All electrical connections from various subsystems (e.g., steam turbine, electrical storage system, etc.) will be routed through the switchyard. The switch yard will contain the necessary logic to appropriately 
connect the hybrid system to the grid as well as balance electricity demands within the hybrid system (e.g., battery and industrial process demands). See Fig. 18.

The switchyard will enable power flow in various directions based on the state of the generation, storage, loads, and grid. Fig. 19 illustrates switching off Load \#2 and the reduced consumption from the grid. Fig. 20 illustrates switching on Load \#2 and the increased consumption on the grid. The effect of generation (shown as negative load) being switched on in the switchyard is shown in Fig. 21.

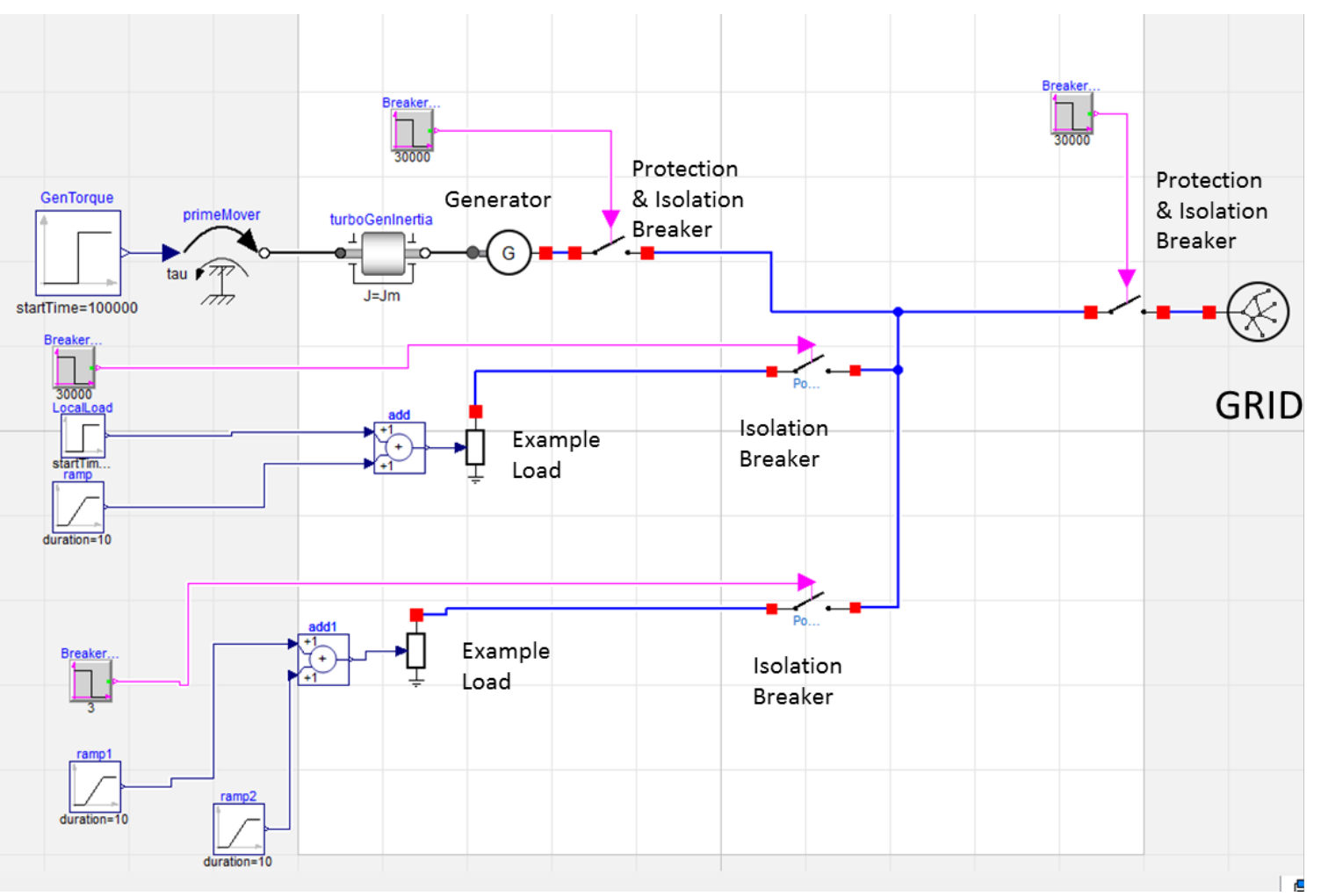

Fig. 18. Switch Yard Model Example.

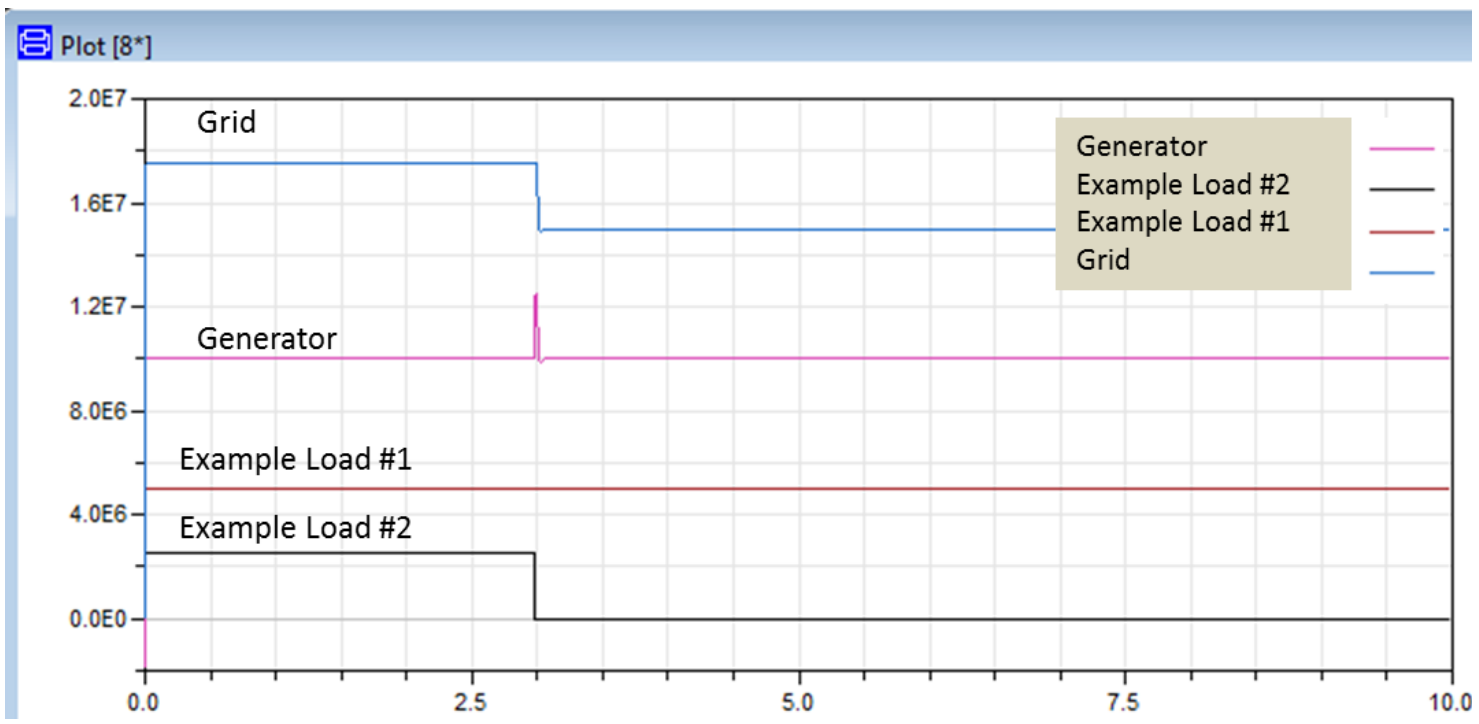

Fig. 19. Switch Yard Model Simulation Example. 


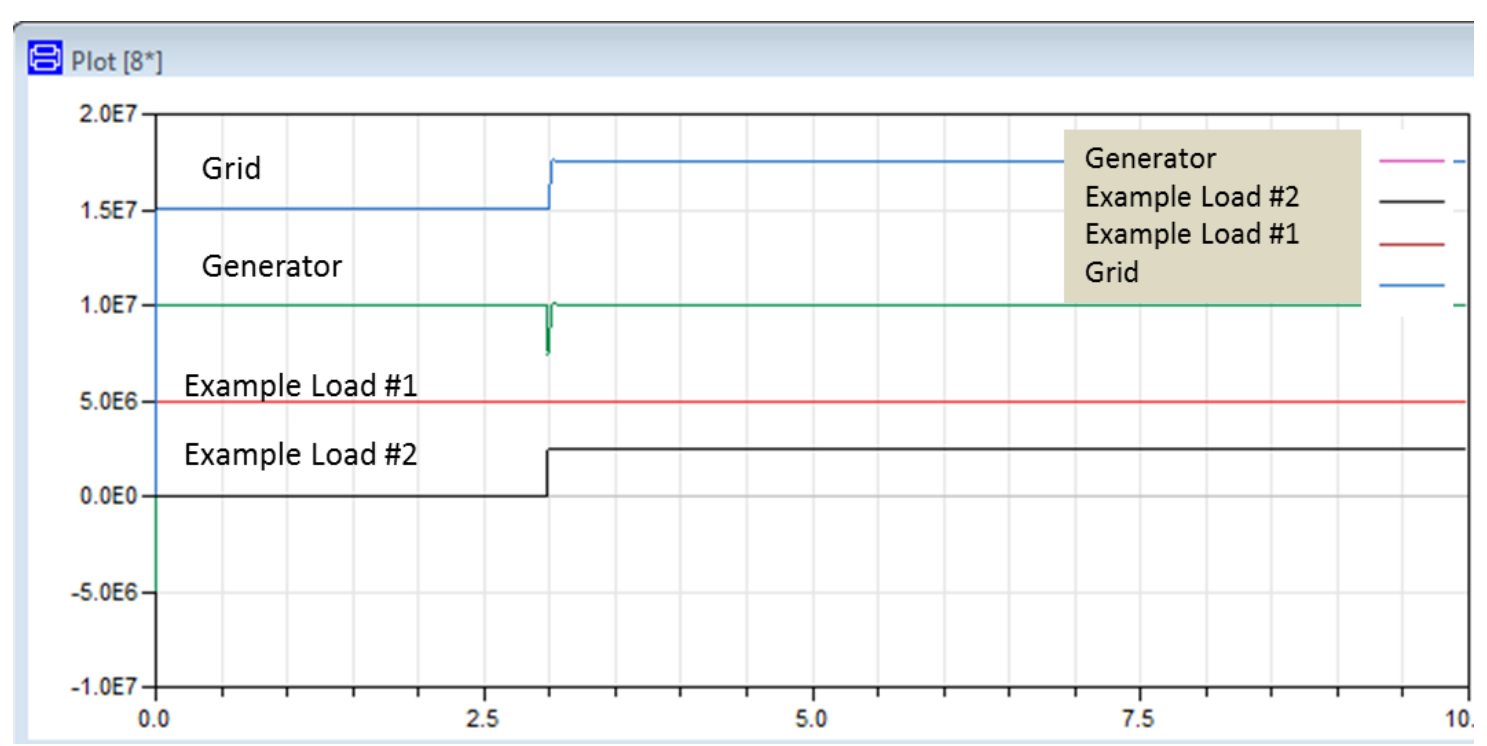

Fig. 20. Switch Yard Model Simulation Example.

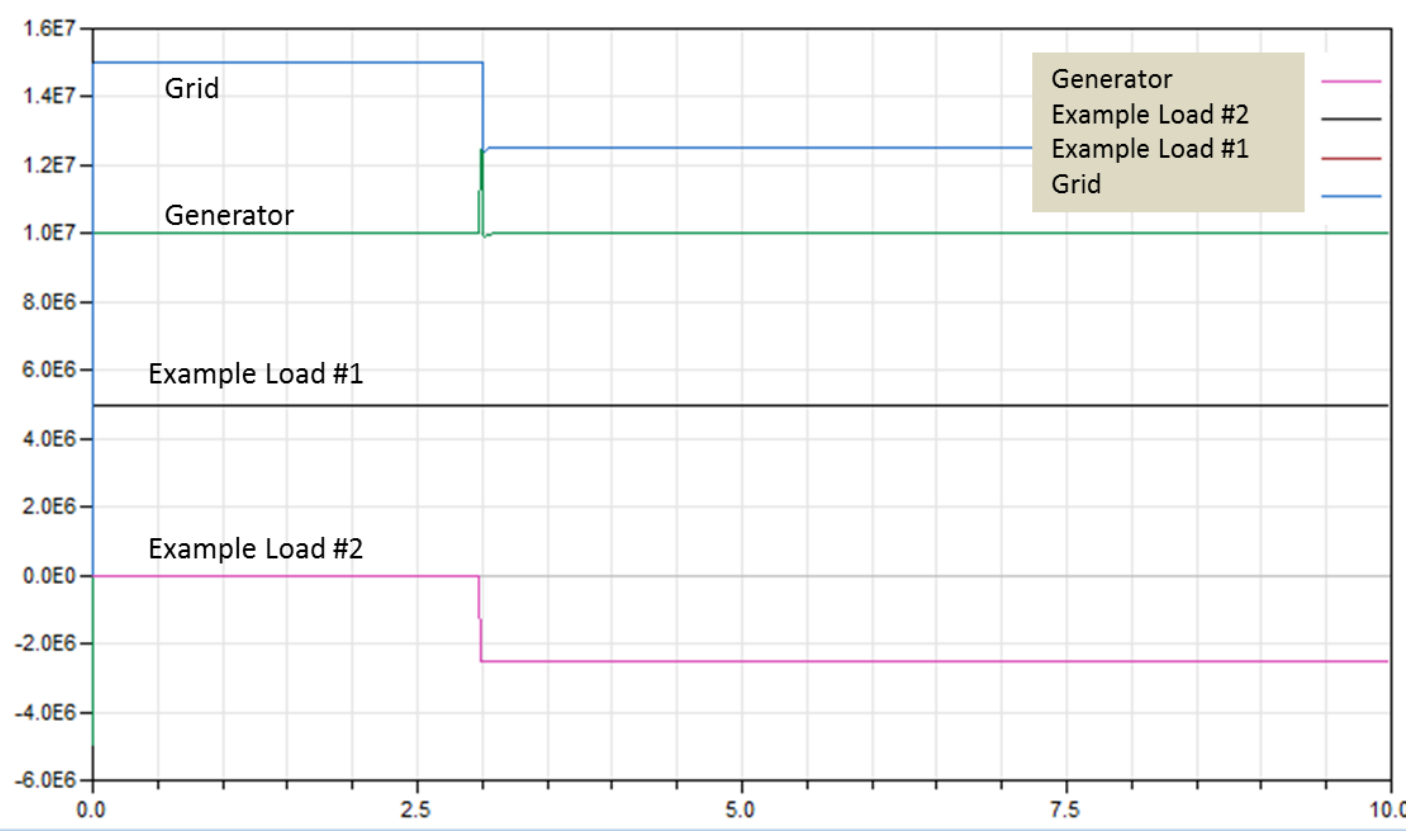

Fig. 21. Switch Yard Model Simulation Example.

\subsection{QUALITY ASSURANCE AND MODEL VERIFICATION}

Version control (e.g., Git) is used throughout model development for quality assurance. The hybrid system work is located on the INL High Performance Cluster Gitlab server. All team members are required to contribute via Git on this server. As part of the model verification process, all models, submodels, etc., are required to have testing on all portions of the code. The process of verifying changes to models will be automated. The primary contact for the quality assurance and model verification is INL. 



\section{NUCLEAR HYBRID ENERGY SYSTEM INSTRUMENTATION AND CONTROL}

Significant work is still required on all systems to identify necessary instrumentation and controls to properly control the hybrid energy system. As the overall system and subsystems mature all necessary information and parameters will be identified and included at the appropriate level in the models. Currently identified requirements for each subsystem are identified in the following sections. More generally, all flows (i.e., fluid/steam, electricity, etc.) between subsystems will be instrumented and will not be discussed explicitly in the subsequent sections.

\subsection{NUCLEAR STEAM SUPPLY INSTRUMENTATION AND CONTROL}

The current hybrid system is designed to operate at a nominal nuclear reactor output. Therefore, the instrumentation and controls of the NSSS and overall supervisory control system will monitor the necessary parameters and implement controls to ensure a steady thermal output at the nominal power level. Parameters and controls include, but are not limited to, core thermal output, effective fuel and coolant temperatures, control rod worth, and pump speed.

\subsection{THERMAL MANIFOLD INSTRUMENTATION AND CONTROL}

Signals will be received from the various subsystems connected to the thermal manifold such as the industrial process and steam turbine. For the current thermal manifold under consideration, the steam manifold, demand signals will specify steam requirements which will then be met via the manipulation of the manifold valve system.

\subsection{POWER CONVERSION SYSTEM INSTRUMENTATION AND CONTROL}

A configuration was developed to test the NSSS model and to add I\&C components. See Fig. 22 below. The NSSS configuration is described as the Primary Heat System (PHS) model shown in Fig. 22. The steam generator inlet and outlet flows were set using source and sink models on the original configuration. Model features were added to support the variation of the steam generator inlet flow for model behavior study. Temperature, mass flow, and volumetric flow instrumentation was added to the steam generator inlet and outlet flow paths.

Instrumentation was added to the NSSS model also as shown in Fig. 23. Fig. 23 illustrates the addition of temperature measurements on the reactor core inlet and outlet and the internal reactor cooling loop steam generator inlet and outlet. Mass flow measurement was added to the reactor core inlet. Pressure measurement was added to the pressurizer interface with the reactor cooling loop.

Validation of the instrumentation was performed by examining the model behavior for two selected transient test cases. A reactivity change was initiated by a control rod change and the steam generator inlet external flow was manipulated. Fig. 24 illustrates the control rod reactivity change test. The instrumentation illustrates that an increase in reactivity causes the reactor core outlet temperature to rise which causes the reactor cooling loop temperature to rise. This affects the rise in temperatures in the steam generator and the associated rise in the steam generator output temperatures. The pressurizer pressure rises also due to the increased reactor cooling loop temperature. 


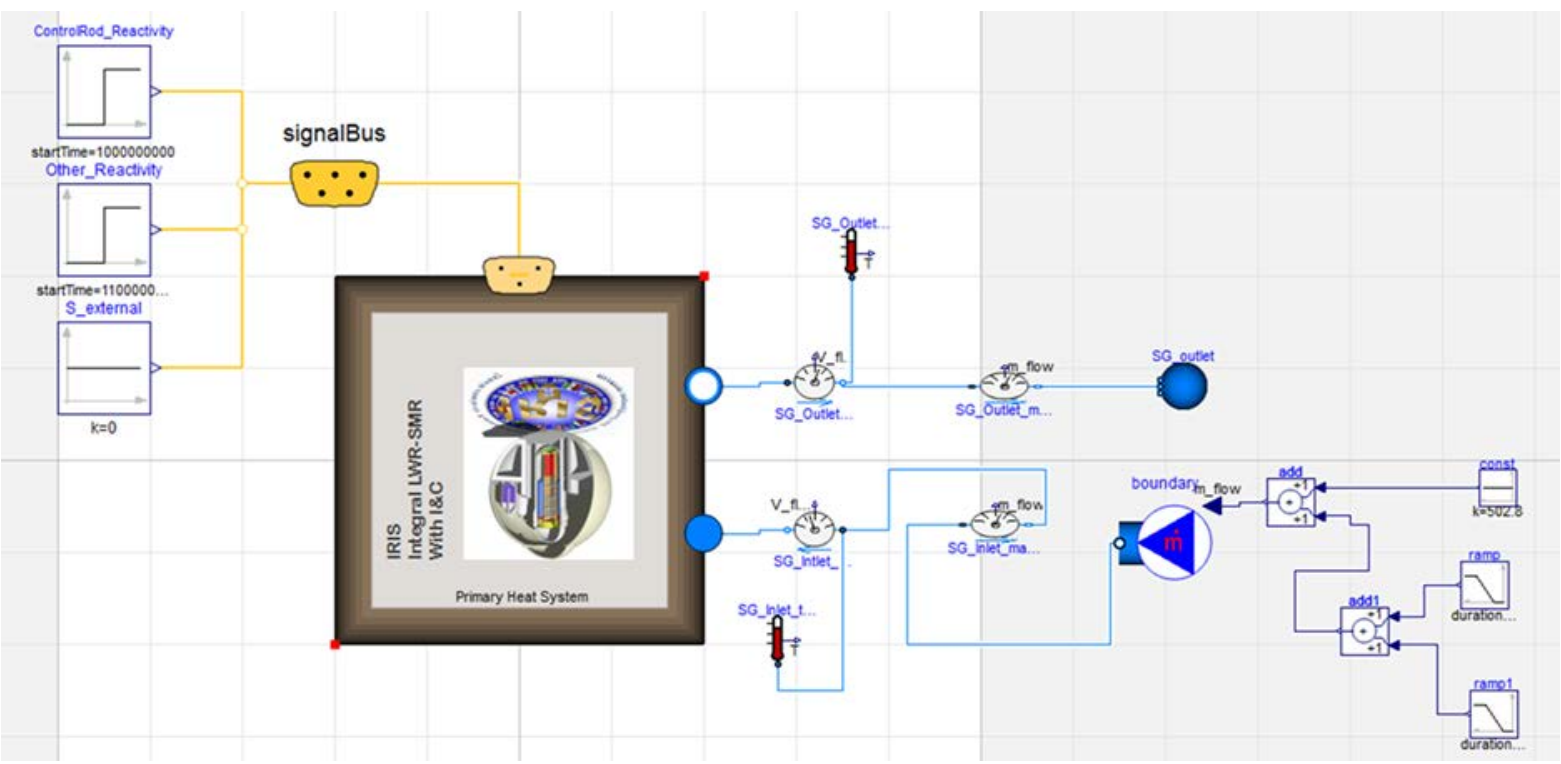

Fig. 22. Test configuration of NSSS model with instrumentation.

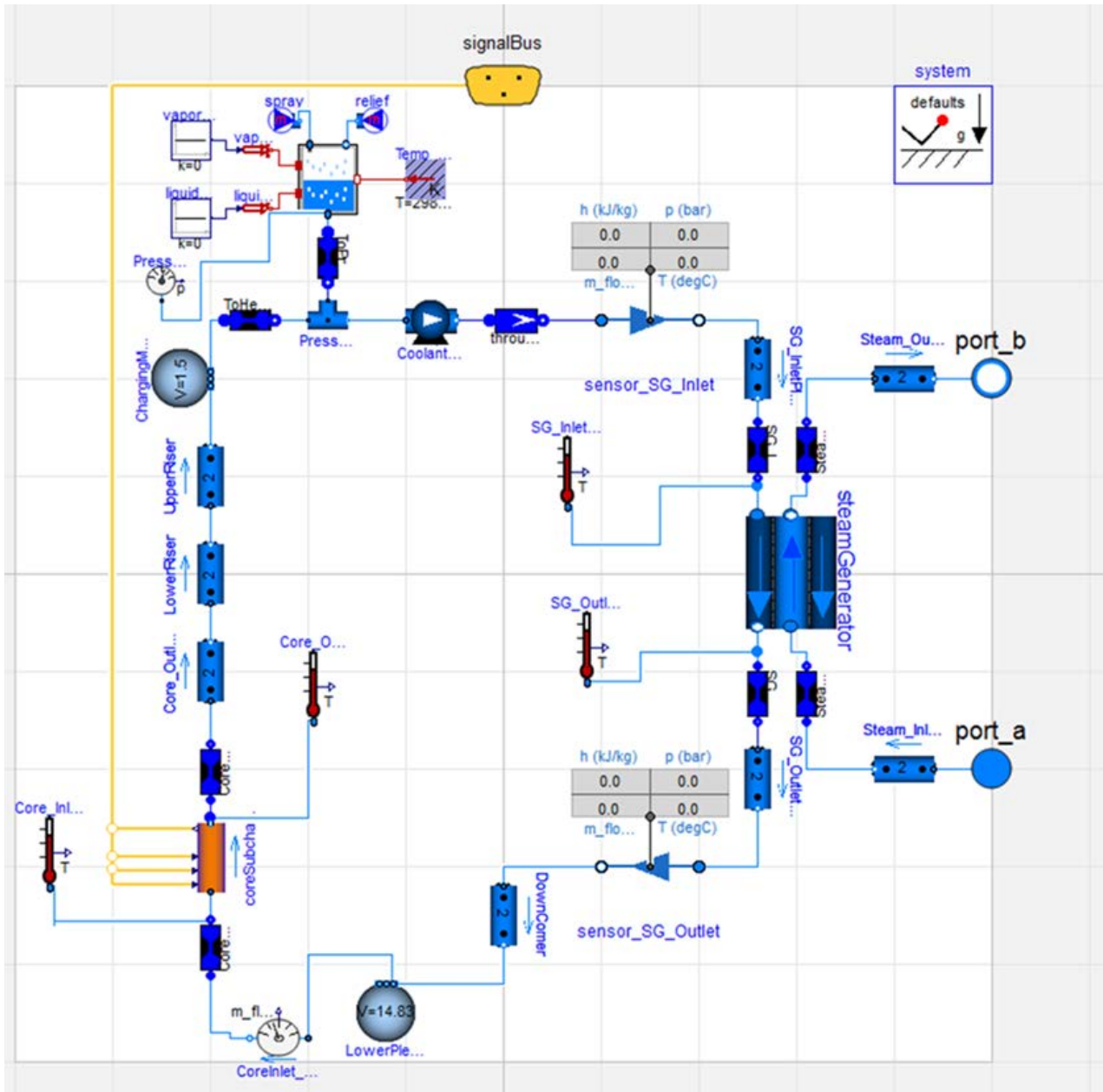

Fig. 23. NSSS model with instrumentation. 
Fig. 25 illustrates the effect of a $2 \%$ increase ramp and a $2 \%$ decrease ramp in the steam generator external input flow. The changes in flow directly decrease and then increase the steam generator external outlet temperatures. This also affects the internal steam generator temperatures by causing a decrease and then an increase in temperature. The core outlet temperature also demonstrates a decrease and then an increase in temperature.

The power conversion system model will include a steam control valve on the steam flow input of the high pressure turbine. In modern power plants, a throttling or governing steam valve is used to adjust the steam pressure and flow supplied to the turbines to regulate a constant speed during varying generation loads. The turbine speed must always be synchronized with the generation frequency. As load changes, the turbine will inherently react to the generation load change with a speed change which requires small amplitude and fast acting control adjustments to the steam input. This control is performed by a steam regulation valve that regulates the direct supply flow into the turbine or a bypass flow path. Fig. 25 illustrates the relationship of the valve area to steam pressure and flow, which ultimately affects the generator speed and the electrical frequency. This approach is not used to vary the actual power output; that is performed by controlling the energy provided to the turbine by the reactor and the heat transport systems.

\section{Steam Generator External}
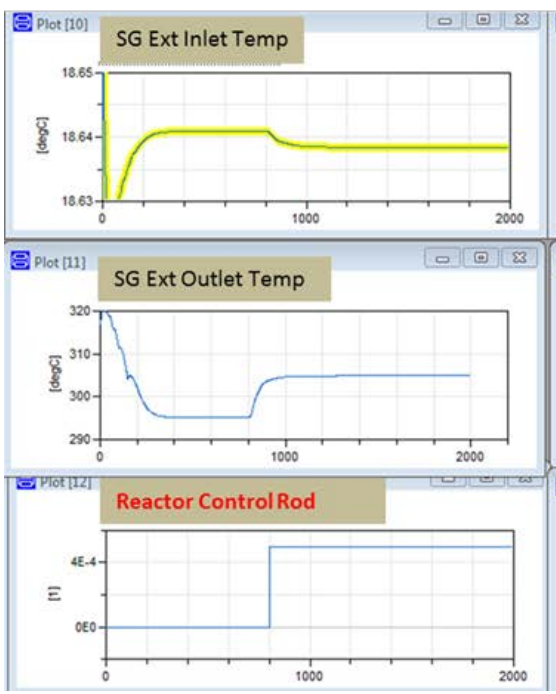

\section{PHS}
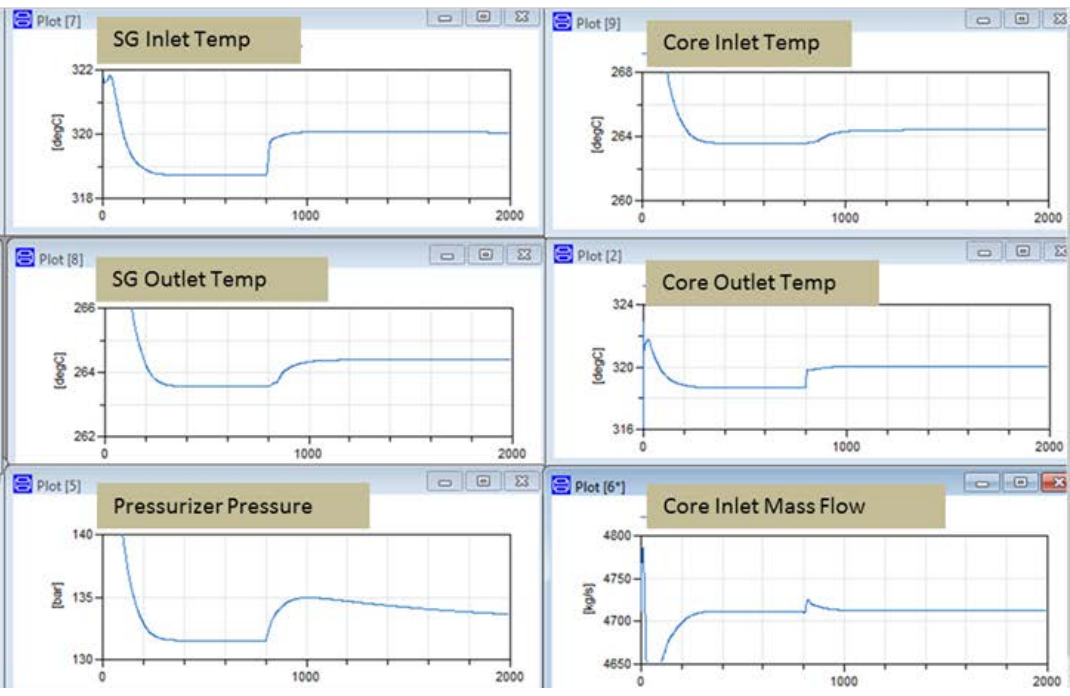

Fig. 24. NSSS model with instrumentation model test with reactivity change test case. 


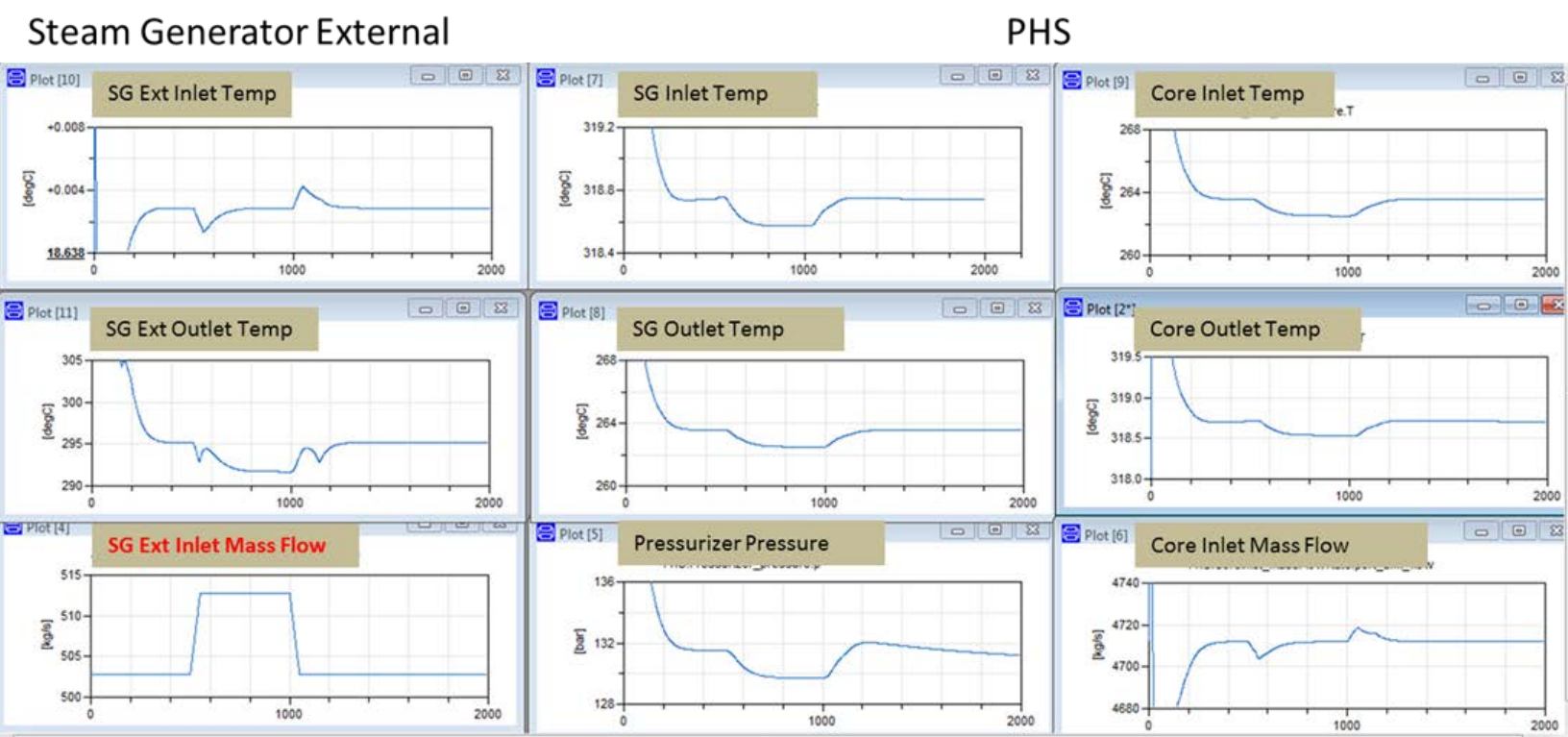

Fig. 25. NSSS model with instrumentation model test with steam generator input flow variation test case.

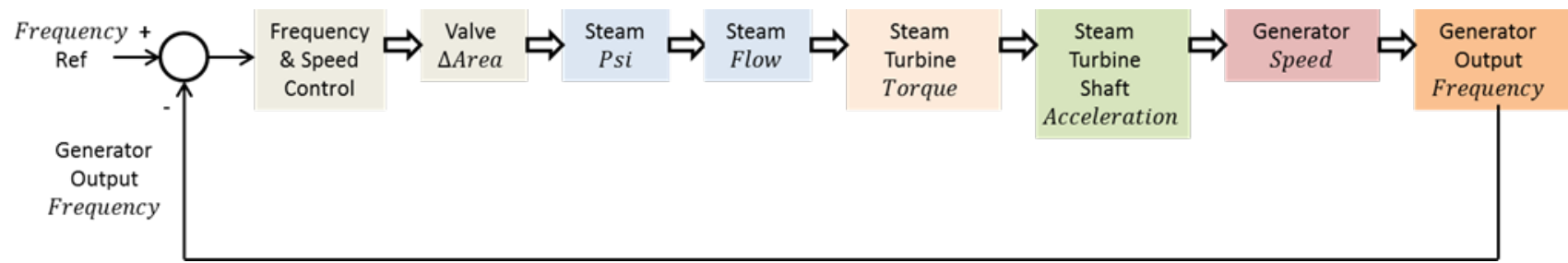

Fig. 26. Turbine speed control concept.

\subsection{OTHER COMPONENT INSTRUMENTATION AND CONTROL}

Additional instrumentation and control will be identified and included for other subsystems as necessary. The industrial process, electrical storage, and auxiliary power generator, for example, will have various operating requirements that will feed into the implemented instrumentation and control strategies. These control strategies may include:

- $\quad$ providing power to customers in some order of preference, such as meeting grid demand before shifting power to the industrial customer, or vice versa

- limiting ramp rates for components or switching systems

- limiting charging/discharging of the battery

- limiting temperature or pressure changes in systems or subsystems

\subsection{SUPERVISORY SYSTEM INSTRUMENTATION AND CONTROL}

At the initialization stage of a simulation, input from RAVEN will frame the operational requirements of the system. In theory, RAVEN could alter nearly any value within the system, including the signals that 
will be part of the control system. In practice, the number of input values will be limited to the defined parameters given in Section 2; this is generally limited to the scaling of the nominal output of components, such as the thermal power of the reactor. A simplified schematic of the communication between RAVEN and the Modelica model is shown in Fig. 27.

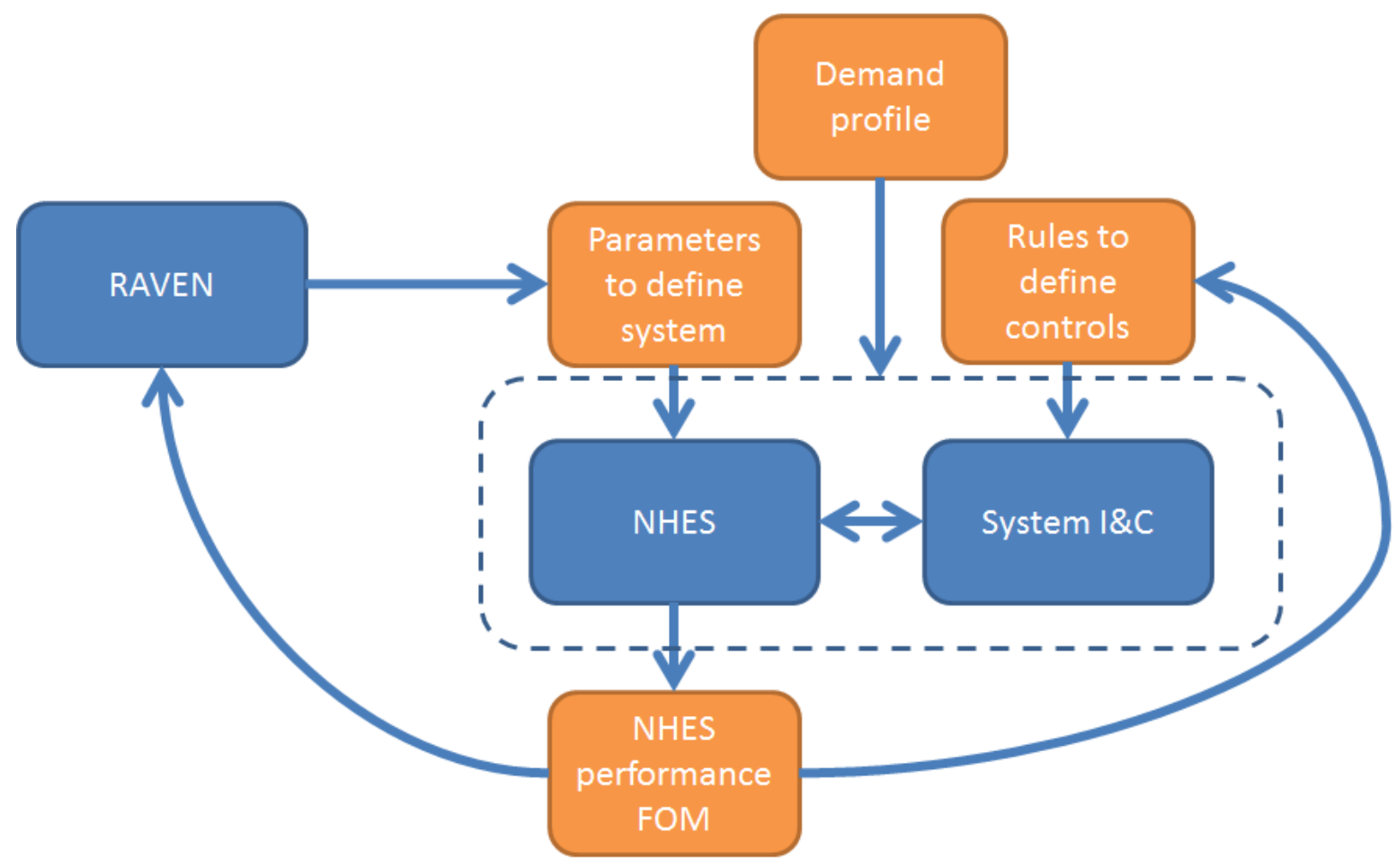

Fig. 27. Nuclear Hybrid Energy System model communication schematic.

In this schematic, RAVEN sends a set of parameters to the NHES model to fix its definition. At the same time, the control system rules are sent to the system I\&C model. The NHES and the system I\&C appear within a dashed line in Fig. 27; this corresponds to their instantiation within the Modelica model. A demand profile is then applied as a boundary condition to the Modelica model, the NHES works to meet the demand profile using the rules, constraints, and control logic set by the system I\&C. Its performance is then calculated using figures of merit (FOM); these FOM are then communicated back to RAVEN for the next optimization iteration, as well as to the rule definition engine.

The optimization process could work with two different iteration loops. One option is to iterate with a fixed set of system parameters while working on the control rules; the other is to fix the control rules while working on the system parameters.

The inputs values are derived from the regional case under consideration and various economic measures that guide size, operation, and performance of the hybrid system. Identified requirements are as follow:

- Time variant grid electricity demand required from the hybrid system

- Time variant fractional electricity supply of each electrical source in the hybrid system

- Nominal capacities of key subsystems (i.e., thermal manifold, steam and natural gas turbine, battery, and industrial process) 
The supervisory system will take the RAVEN input data and manipulate subsystem controls as necessary using proper instrumentation. Important parameters associated with reliability and other figures of merit will be gathered during the simulation and provided as input to RAVEN is economic calculations and optimization routines; this provides the feedback arrow shown in the lower left of Fig. 27. 


\section{NUCLEAR HYBRID SYSTEM FIGURES OF MERIT}

For the hybrid energy systems figure of merits can be categorized based on environmental, economic, technical and socio-political aspects. The indices under each category help users to select among similar systems with common applications and/or to determine hybrid system performance. These FOMs can also be used to analyze performance versus stand-alone systems.

For this work, economical and technical FOMs are selected for the Nuclear Hybrid Energy Systems (NHES) Regional Studies. The economical and technical FOMs selected at the 2014 workshop for West Texas \& Northeastern Arizona [14] were:

- Electric power frequency stability

. Maximum renewable penetration that can be accommodated

. Maximum renewable variability that can be accommodated

. Minimum storage requirement

- Response time and ramp-rate

- Load following response

- Operating reserve capacity

. Minimum turndown of integrated systems

- Startup/shutdown time

. Pre-tax gross profit

. Net present value

Economical

. Payback time

. Internal rate of return

The FOM analysis developed [15] for a hybrid geothermal-fossil fuel plant is commonly used for such assessments. This analysis is limited to only technical FOM. The report by Zhoul [16] incorporates economical FOM for the same system, and the analysis was performed to compare the power output and capital cost of the hybrid plant with the state-of-the-art and existing stand-alone solar and geothermal plants. Technical and economical FOMs analyses of NHES are reported in [17].

Reliability as a figure of merit is another important approach, but based on a literature search it is not analyzed for the NHES. To calculate reliability FOM of the NHES, an approach is proposed [18]. A flowchart of this approach is shown in Fig. 28. 


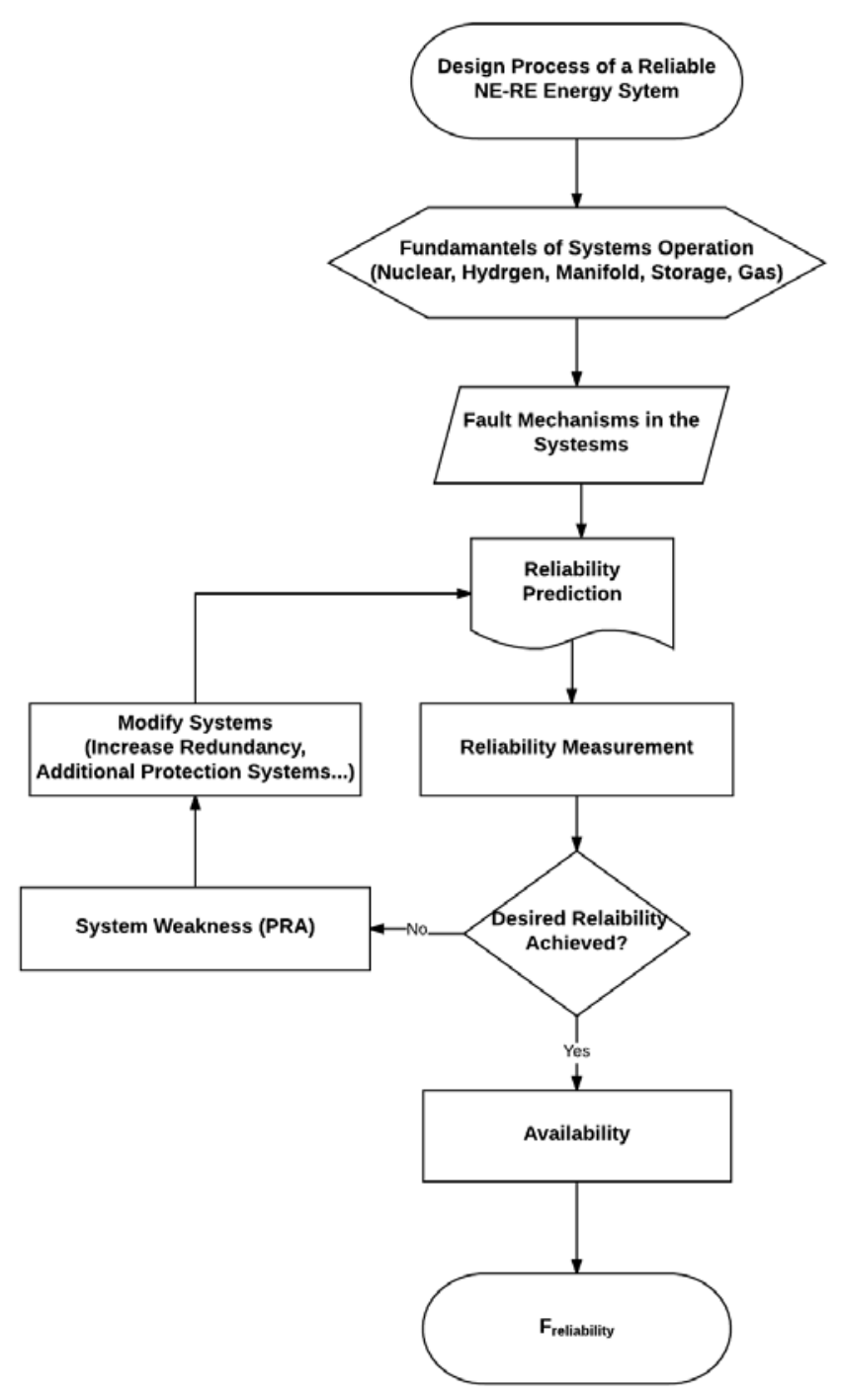

Fig. 28. Reliability figures of merit qualification flow chart.

The new figure of merit can provide better insight into the assessment of the NHES over the stand-alone nuclear power plants or renewable systems. Additionally, the translation of the technical figures of merit into economic figures of merit requires additional study and assumptions. For example, the use of electrical power frequency stability as a FOM can be quantified by generating a statistical distribution of 
measured electrical power frequency; the variance (and higher moments) for this distribution provide a measure of the stability which can be directly compared among multiple scenarios.

However, the cost of frequency instability likely shows step function costs because it serves as a threshold effect; once frequency moves outside an acceptable range, system effects occur regardless of the actual frequency. For example, frequencies less than $59.3 \mathrm{~Hz}$ trigger the first level of under-frequency load shedding [19], regardless of the actual frequency.

Additionally, the response time and ramp rate of system resources may not have an operations cost associated with them, but would rather offset the need to purchase external power production resources or would allow more faithful adherence to the shifting needs of the system. Conversely, the frequent exercising of the system with power shifts may decrease the overall reliability and lifetime of the system, leading to increased capital costs due to replacement of capital equipment. 



\section{ONGOING AND FUTURE WORK}

\subsection{INTEGRATION WITH EXTERNALLY-GENERATED MODELS}

The model shown and described in Section 2, and attached in Appendix A, represents the system-level flowsheet. ORNL is working to develop the reactor, manifold, balance of plant, and switch yard models for implementation in Modelica. ANL is developing the storage battery model, and INL is developing the hydrogen production and gas turbine models.

ORNL will work to integrate the ANL and INL models in the overall Modelica model. This process requires the definition of interfaces among the different sub-system models for the transfer of mass, energy, instrumentation, and control variables for overall system function.

The overall system function is controlled by a supervisory control system. It is this control system that is altered to seek the optimization of the performance relative to the figures of merit.

\subsection{INTEGRATION WITH RAVEN}

The figure in Appendix A shows the connection between RAVEN and the control system. RAVEN will be the overall analytical and optimization driver for the system. This interface and optimization system will be developed and implemented by INL.

\subsection{CASE ANALYSIS}

Once all the sub-systems have been integrated, the initial case analyses can commence. The initial case analysis will calculate figures of merit based on an input demand profile. 



\section{REFERENCES}

1. https://www.eia.gov/electricity/monthly/update/wholesale markets.cfm, accessed August 2016.

2. http://www.eia.gov/todayinenergy/detail.cfm?id=24492, accessed August 2016.

3. Westinghouse, “Computer Models for IRIS Control System Transient Analysis,” STD-AR-06-04, 2007.

4. C. Rabiti, et al, "Reactor Analysis and Virtual Control Environment (RAVEN) FY12 Report," INL/EXT-12-27351, September 2012.

5. International Atomic Energy Agency (IAEA), “IRIS Plant Overview,” October, 2002.

6. M. D. Carelli, B. Petrović, N. Čavlina, and D. Grgić, "IRIS (International Reactor Innovative and Secure) - Design Overview and Deployment Prospects,” Nuclear Energy for New Europe International Conference, Bled, Slovenia, Sep. 5-8, 2005.

7. A. C. O. Barroso, B. D. Baptista F., I. D. Arone, L. A. Macedo, P. A. B. Sampaio, and M. Moraes, “IRIS Pressurizer Design,” International Congress on Advances in Nuclear Power Plants (ICAPP), paper 3227, Córdoba, Spain, May 4-7, 2003.

8. A. C. O. Barroso and B. D. Baptista F., "Refining the Design and Analysis of the IRIS Pressurizer," $5^{\text {th }}$ International Conference on Nuclear Option in Countries with Small and Medium Electricity Grids, Dubrovnik, Croatia, May 16-20, 2004.

9. A. C. O. Barroso, D. A. Botelho, P. A. B. De Sampaio, and M. Moreira, "Simulation of IRIS Pressurizer Out-Surge Transient Using Two and Three Volumes Simulation Models," International Nuclear Atlantic Conference (INAC), Santos, Brazil, Aug. 28-Sep. 2, 2005.

10. A. Cioncolini, A. Caami, L.Cinotti, G. Castelli, C. Lombardi, L. Luzzi, and M. Ricotti, "Thermal Hydraulic Analysis of IRIS Reactor Coiled Tube Steam Generator,” Proc. Of Nuclear Mathematical and Computational Sciences: A Century in Review, A Century Anew, LaGrange Park, Ill, April 6-11, 2003.

11. IRIS Plant Overview, October 17, 2002, http://www.nrc.gov/docs/ML0336/ML033600086.pdf.

12. R. Hale, et. al., Update on ORNL TRANSFORM Tool: Preliminary Architecture / Modules for HighTemperature Gas-Cooled Reactor Concepts and Update on ALMR Control, August 2015, ORNL/SPR-2015/367.

13. ThemoPower, Open Library for Thermal Power Plant Simulation, Politecnico di Milano, http://thermopower.sourceforge.net/.

14. S. Bragg-Sitton, R. Boardman, M. Ruth, O. Zinaman, C. Forsberg, and J. Collins, Integrated NuclearRenewable Energy Systems: Foundational Workshop Report, INL/EXT-14-32857 Rev. 1, NREL/TP6A20-62778, August 2014.

15. H. E. Khalifa, R. Dipippo, and J. Kestin, Geothermal preheating in fossil-fired steam power plants, Proceedings of the $13^{\text {th }}$ Intersociety Energy Conversion Engineering Conference, Warrendale, PA, USA, 1978.

16. C. Zhou1, E. Doroodchi, and B. Moghtaderi, "Figure of Merit Analysis of a Hybrid Solar-Geothermal Power Plant, Engineering,” 2013.

17. C. Rabiti, R. A. Kinoshita, J. S. Kim, W. Deason, S. M. Bragg-Sitton, R. D. Boardman, and H. E. Garcia, Status on the Development of a Modeling and Simulation Framework for the Economic Assessment of Nuclear Hybrid Energy Systems, INL/EXT-15-36451, September 2015. 
18. S. Kaboli and H. Oraee, Reliability as a Figure of Merit. In Reliability in Power Electronics and Electrical Machines: Industrial Applications and Performance Models, In Reliability in Power Electronics and Electrical Machines: Industrial Applications and Performance Models, 231-261, 2016.

19. M. Hanley, "Frequency Instability Problems in North American Interconnections,” DOE/NETL2011/1473, May 2011. 
APPENDIX A. NHES PROCESS AND INSTRUMENTATION DIAGRAM 



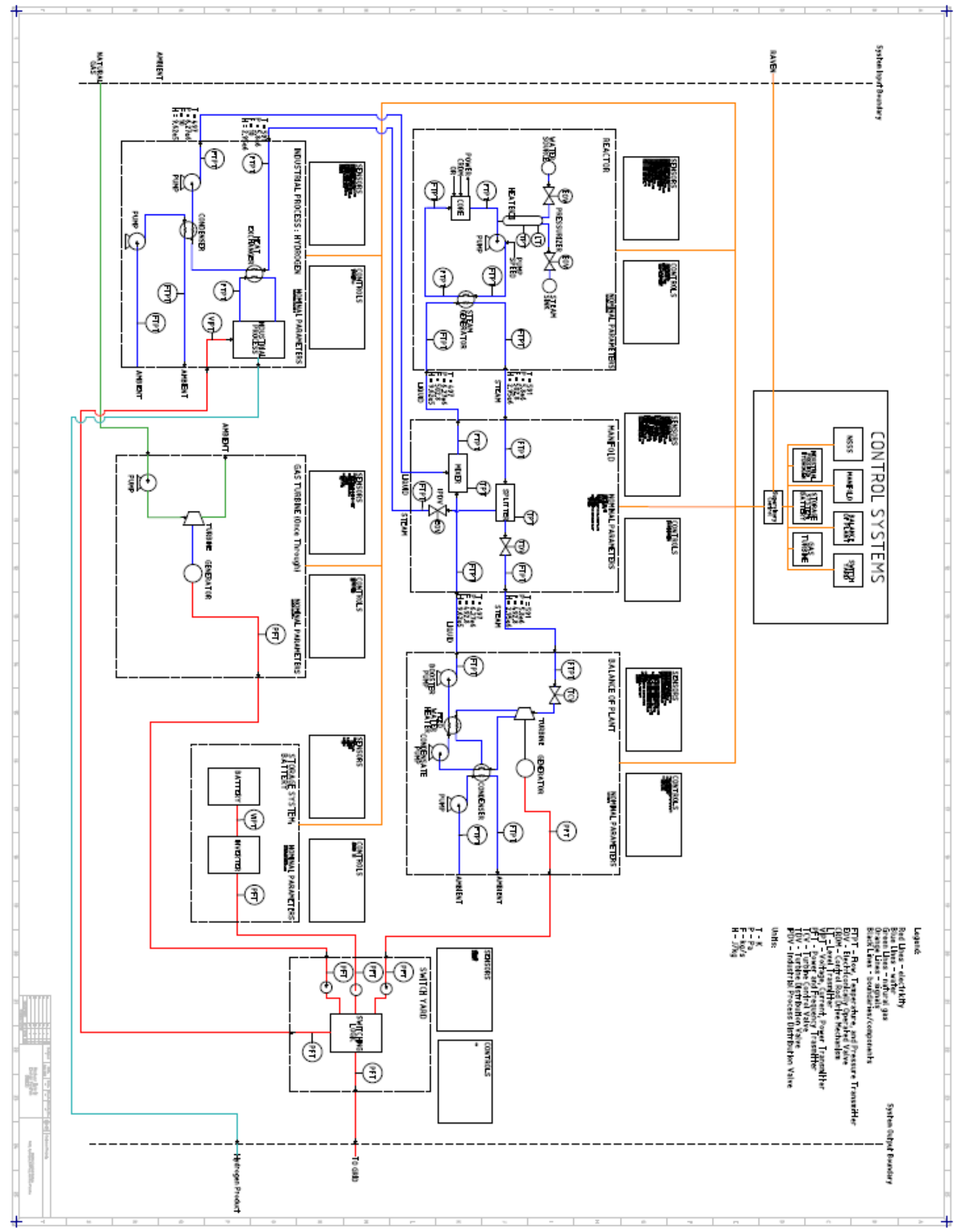

A-3 